\title{
Spatial optimization of watershed best management practices based on slope position units
}

\author{
C.-Z. Qin, H.-R. Gao, L.-J. Zhu, A-X. Zhu, J.-Z. Liu, and H. Wu
}

\begin{abstract}
Spatial optimization of best management practices (BMPs) is an effective way to select and allocate BMPs for watershed management such as soil and water conservation and nonpoint source pollution reduction. The commonly used spatial units for BMP configuration (or BMP configuration units) include subbasins, hydrologic response units (HRUs), farms, and fields. Normally, these spatial units are not homogeneous functional units from the perspective of physical geography at the hillslope scale (in terms of geomorphic and hydrologic conditions of the hillslope, for example), and thus cannot effectively represent the spatial relationships between BMPs and spatial locations with respect to hillslope processes from upstream to downstream. This makes it difficult to efficiently and rationally construct spatial optimizations for watershed BMPs. This paper proposes a spatial BMP optimization approach based on slope position units, which are homogeneous spatial units with physical geographic features. In the proposed approach, slope position units are used as BMP configuration units by which the relationships between BMPs and slope positions along a hillslope can be explicitly considered during BMP scenario initialization and optimization via genetic algorithm (i.e., NSGA-II). A distributed and physically based watershed model was used to evaluate the environmental effectiveness (i.e., the reduction rate of soil erosion), and a simple estimation method was developed to calculate the net cost of BMP scenarios. A case study was conducted in a small hilly watershed in the typical red-soil region of the Fujian Province in southeastern China, which suffers severely from soil erosion. A simple system of three types of slope positions (i.e., ridge, backslope, and valley) was used to delineate BMP configuration units. Four BMPs that are used in actual Chinese red-soil regions (closing measures, arborbush-herb mixed plantation, low-quality forest improvement, and orchard improvement) were considered in the proposed approach to achieve the multiple optimization objectives, which included maximizing the reduction ratio of soil erosion and minimizing the net cost of the BMP scenario. The proposed approach was compared with the standard random optimization approach, which selects and allocates BMPs randomly on BMP configuration units. The results show that the proposed approach is more effective and efficient for proposing practical and effective BMP scenarios than the random approach.
\end{abstract}

Key words: best management practices—genetic algorithm—slope position units—spatial optimization-watershed process simulation

Best management practices (BMPs) are a series of management practices that are implemented at different spatial scales (e.g., site, field, streambank, and subbasin) to control soil erosion, reduce nonpoint source pollution, and protect the ecological environment of a watershed (Gitau et al. 2004; Turpin et al. 2005; Arabi et al. 2006; Panagopoulos et al. 2012). Spatial optimization of BMPs based on watershed modeling coupled with intelligent optimization algorithms (e.g., NSGA-II [Deb et al. 2002]) is an effective watershed management planning approach to proposing optimal BMP scenarios (i.e., selection and allocation of multiple BMPs for spatial units in watershed) as a balance between consideration of both environmental effectiveness and cost-benefit (Veith et al. 2004; Duinker and Greig 2007; Maringanti et al. 2011). Watershed models are used to simulate the watershed response (e.g., flow, sediment, nitrogen $[\mathrm{N}]$, and phosphorus $[\mathrm{P}]$ ) to each BMP scenario and then evaluate its environmental effectiveness. One of the key elements that affects how a watershed responds to a BMP scenario is the spatial configuration of its BMPs on spatial units in the watershed (Heathwaite et al. 2000; Sahu and $\mathrm{Gu} 2009)$.

The commonly used spatial units for BMP configurations (hereafter called BMP configuration units) in existing studies of spatial BMP optimization include subbasins (Chang et al. 2007; Chichakly et al. 2013), hydrologic response units (HRUs) (Maringanti et al. 2011), farms (Gitau et al. 2004), and fields (Srivastava et al. 2003; Kalcic et al. 2015b; Wu et al. 2018). A subbasin is normally regarded as a relatively closed and independent spatial unit. A subbasin consists of hillslopes, which can be further delineated into different homogeneous functional units from the perspective of physical geography (such as geomorphic, soil, and hydrologic conditions), e.g., landform positions (Band 1999). Since individual BMPs are often more effec-

Cheng-Zhi Qin is a professor at the State Key Laboratory of Resources and Environmental Information System (LREIS), the Institute of Geographic Sciences and Natural Resources Research (IGSNRR), the Chinese Academy of Sciences; the University of Chinese Academy of Sciences (UCAS) in Beijing, China; and the Jiangsu Center for Collaborative Innovation in Geographical Information Resource Development and Application in Nanjing, China. HuiRan Gao is a graduate student at the LREIS, the IGSNRR, the Chinese Academy of Sciences; and the UCAS in Beijing, China. Liang-Jun Zhu (corresponding author) is a doctoral student at the LREIS, the IGSNRR, the Chinese Academy of Sciences; and the UCAS in Beijing, China. A-Xing Zhu is a professor at the Key Laboratory of Virtual Geographic Environment (VGE), Ministry of Education, Nanjing Normal University, Nanjing, China; the Jiangsu Center for Collaborative Innovation in Geographical Information Resource Development and Application in Nanjing, China; the LREIS, the IGSNRR, the Chinese Academy of Sciences, Beijing, China; and the Department of Geography, University of WisconsinMadison. Jun-Zhi Liu is an associate professor at the Key Laboratory of VGE, Ministry of Education, Nanjing Normal University, Nanjing, China; and the Jiangsu Center for Collaborative Innovation in Geographical Information Resource Development and Application, Nanjing, China. Hui Wu is a lecturer at the Smart City Research Center, Hangzhou Dianzi University, Hangzhou, China. 
tive when applied to specific homogeneous functional units, the subbasin unit is too general for spatially explicit BMP configurations.

HRUs represent hydrologic homogeneous areas combined in terms of land use, soil, and slope within one subbasin (Arnold et al. 1998). One HRU may occupy several parts on a hillslope (e.g., separate ridge and valley areas), and HRUs are not internally linked within one subbasin (Arnold et al. 2010; Bieger et al. 2016). This characteristic means that the impact of spatial relationships between BMP configuration units (e.g., the impact of upslope BMPs on downslope units) cannot be effectively assessed when those units are HRUs (Arnold et al. 2010). Therefore, the HRU is incapable of being the BMP configuration unit for spatially explicit BMP configurations, especially for those BMPs (e.g., conservation management systems) that have different effects on locations with various topographic, land use, or soil conditions (Heathwaite et al. 2000; Jiang et al. 2007; Mudgal et al. 2010).

Farms and fields are often defined according to land ownership, current land use, or soil type boundaries (Srivastava et al. 2003; Gitau et al. 2004; Kalcic et al. 2015a; Wu et al. 2018). A farm or field may be delineated roughly across multiple landform positions or subbasins (Srivastava et al. 2003; Kalcic et al. 2015a; Wu et al. 2018), which results in weak spatial relationships to homogeneous functional units. Such delineated spatial units face shortcomings similar to those faced by subbasins and HRUs. Occasionally, farms or fields are delineated as a patchwork of gridded cells (even as individual gridded cells; Gaddis et al. 2014) within homogeneous functional units. This results in a large number of BMP configuration units, which can make the spatial optimization process computationally intensive or even unsolvable (Gaddis et al. 2014; Wu et al. 2018).

Therefore, the spatial units for BMP configurations should be homogeneous functional units with a comparatively limited count per study area, and currently used BMP configuration units are not suitable. In this study, we propose to use slope positions as the spatial units for BMP configurations. There are two main reasons for this selection: (1) the physical geographic features of spatial units, and (2) the computational requirements of BMP optimization based on the spatial units. With respect to the first point, slope positions (also referred as landform positions) are spatially contiguous and topographically connected units along hillslope (e.g., ridge, backslope, and valley). Slope positions, which are basic landform units in a hierarchical structure of spatial units (i.e., slope position, hillslope, subbasin, and so on), inherently relate to physical watershed processes (Swanson et al. 1988; Band 1999; Qin et al. 2009; Ajami et al. 2016; Bieger et al. 2016). Slope positions affect various hillslope-scale processes (e.g. surface runoff and soil erosion, Mudgal et al. 2010) and hence affect both soil hydrologic properties (Jiang et al. 2007; Qin et al 2012; Geng et al. 2017) and the effectiveness of BMPs (Bosch et al. 2012; HernandezSantana et al. 2013). Researchers have suggested considering the characteristics of both BMPs and slope positions during the selection and allocation of BMPs (Berry et al. 2005; Goddard 2005; Pennock 2005; Mudgal et al. 2010). For example, Cai et al. (2012) empirically summarized the spatial relationships between BMPs and slope positions based on the characteristics of soil erosion in the Chinese red-soil region and the practical management experiences of soil and water conservation in this region. According to the integrated management scheme (figure 1) proposed by Cai et al. (2012), natural restoration and ecologic forest-grass management schemes are suitable on the upslope, development management practices such as economical forest-fruit could be conducted on the midslope, while terrace and riparian buffer strips are proper BMPs for the downslope. The other reason for considering slope positions as spatial units is that under a specific system of slope positions, the number of slope positions in a study area is normally limited and much lower than the count of gridded cells for the area. This can reduce the search space during spatial optimization and save computing resources. Thus, slope position units should be the proper spatial units for BMP configuration.

Currently, slope positions have not been used as BMP configuration units for spatial optimizations of BMPs at the watershed scale, although slope position units have been integrated into process-based distributed watershed models, such as the restructured version of Soil and Water Assessment Tool (SWAT+) (Bieger et al. 2016) and Soil Moisture And Runoff simulation Toolkit (SMART) (Ajami et al. 2016). A few studies examined the effectiveness of BMPs on different slope positions based on water- shed modeling by manually designed BMP scenarios (Sahu and Gu 2009; Mudgal et al. 2010). For example, using SWAT with a hillslope-discretization scheme, Sahu and $\mathrm{Gu}$ (2009) examined the effect of both size (i.e., $10 \%, 20 \%, 30 \%$, and $50 \%$ of subbasin area) and spatial location (i.e., the midway of the hillslope or riparian buffer) of filter strips on reducing nitrate- $\mathrm{N}\left(\mathrm{NO}_{3}-\mathrm{N}\right)$ in an agricultural watershed. In the study by Sahu and $\mathrm{Gu}$ (2009), the midway of the hillslope was defined as a percentage of subbasin area instead of a homogeneous functional unit. Thus, this method of BMP allocation is not spatially explicit. Mudgal et al. (2010) used the Agricultural Policy/Environmental eXtender (APEX) model to evaluate the impact of different slope position sequences (e.g., summit-backslope-footslope, footslope-backslope-summit, and so on) and the sizes of slope positions on the simulation of runoff and dissolved atrazine load at 30 designated plots with a size of $189 \times 18$ $\mathrm{m}$. Although the slope position sequences considered in Mudgal et al. (2010) were theoretical and some of them may not exist naturally (e.g., backslope-footslope-summit), their results still indicated that taking account of slope positions may be beneficial when making management decisions.

In this study, we examined the effectiveness of using slope positions as BMP configuration units in the spatial optimization of BMPs for mitigating soil erosion at the watershed scale. The spatial optimization of watershed BMPs based on slope position units was designed as a methodological framework and then was implemented in a case study area by the following tasks: (1) delineating slope position units from gridded digital elevation models (DEMs) of the study area; (2) spatially distributed watershed modeling for simulating watershed processes related to soil erosion in the study area, which was used to evaluate the environmental effectiveness of each BMPs scenario; (3) developing a knowledge base of BMPs considered in the study area, which contains the spatial relationships between BMPs and slope positions; and (4) adopting a multiobjective optimization method to apply the BMP knowledge base to optimizing BMP scenarios based on slope position units. The optimization results of the proposed approach were compared with those from the standard random optimization approach, which selects and allocates BMPs randomly to configuration units. 


\section{Figure 1}

Illustration of an integrated management scheme for soil and water conservation in southeast China (adapted from Cai et al. [2012]).

\section{Natural restoration}

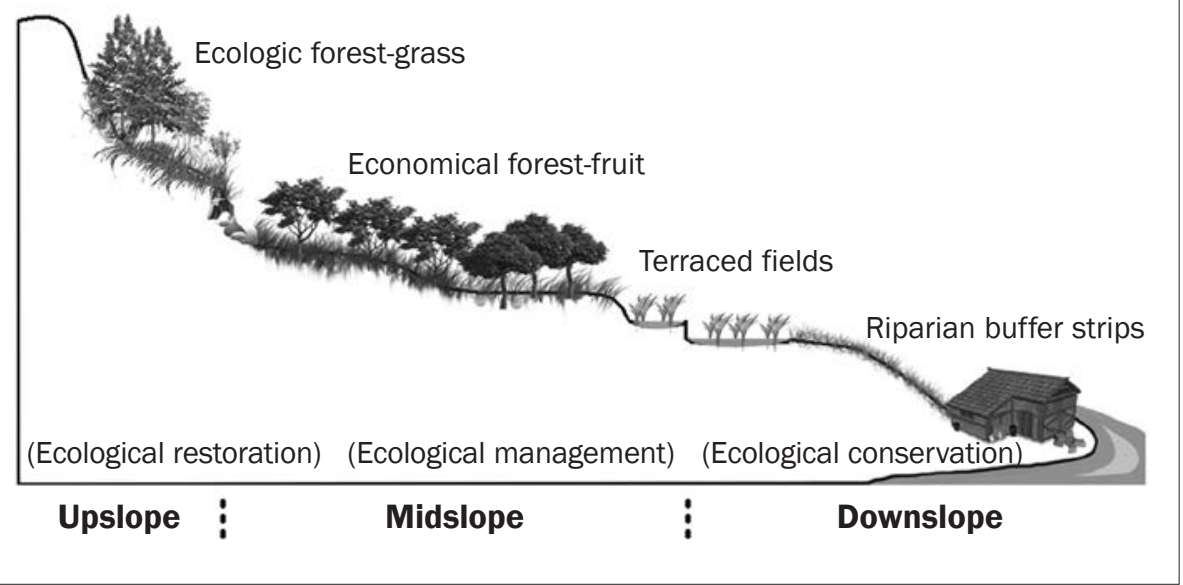

\section{Materials and Methods}

Methodology. To use slope positions as BMP configuration units during spatial optimization of BMPs at the watershed scale, the design of such a new approach should deal with three key issues, which are different from those in the currently used approach. The first is how to delineate slope positions for an area. There are several methods of delineating slope positions by digital terrain analysis on DEMs in a manner of either crisp or fuzzy classification (Pennock et al. 1987; Schmidt and Hewitt 2004; Qin et al. 2009; Miller and Schaetzl 2015).

The second is to formalize the knowledge of the spatial relationships between BMPs and slope positions, which can be stored together with other BMP knowledge in a BMP knowledge base and then applied to the multiobjective optimization process. The spatial relationships between BMPs and slope positions can be summarized as two main types: the suitable BMPs for each type of slope position, and the spatial constraint among BMPs on different types of slope position (normally along the hillslope from upstream to downstream; e.g., if a BMP is placed in a downslope unit, there is no need to place BMPs in its adjacent upslope units [Wu et al. 2018]). This knowledge of the spatial relationships between BMPs and slope positions can be formalized as rules and stored in the BMP knowledge base.

The third is how to combine the formalized knowledge of the spatial relationships between BMPs and slope positions with intelligent optimization algorithms. Note that intelligent optimization algorithms applied to spatial BMP optimization normally initialize and generate BMP scenarios through selecting and allocating BMPs randomly to spatial configuration units. When knowledge of the spatial relationships between BMPs and slope positions is available in the form of rules, those BMP scenarios generated and evaluated by intelligent optimization algorithms will be constrained by this knowledge. Thus, many unreasonable BMP scenarios will not be considered in the multiobjective optimization process, which results in greater optimization efficiency. In addition, the optimal BMP scenarios resulting from such a process are more likely to be reasonable and practical.

Based on the ideas presented above, the framework for the spatial optimization of watershed BMPs based on slope position units proposed in this study is shown in figure 2. The following parts of this section will describe the implementation of the proposed methodological framework in a case study area.

Study Area. The Youwuzhen watershed $\left(\sim 5.39 \mathrm{~km}^{2}\right)$, which is a part of Zhuxi watershed within Changting County of Fujian Province, was chosen as the study area (figure 3). The study area is located in the typical red-soil hilly region in southeastern China and suffers from severe soil erosion (Chen et al. 2013). Its primary geomorphological characteristics include low hills average slope of $16.8^{\circ}$ ) and broad alluvial valleys. The elevation ranges from 295 to $556.5 \mathrm{~m}$. The study area is under a midsubtropical monsoon moist climate. The annual average temperature is $18.3^{\circ} \mathrm{C}$. The annual with steep slopes (up to $52.9^{\circ}$ and with an average precipitation is $1,697 \mathrm{~mm}$, while intense short-duration thunderstorm events contribute about three quarters of annual precipitation from March to August (Chen et al. 2013). The main land use types are forest, paddy field, and orchard, with an area ratio of $59.8 \%, 20.6 \%$, and $12.8 \%$, respectively. Forests in the study area are mostly secondary or human-made forests with scattered Masson's pine (Pinus massoniana) (Chen et al. 2013, 2017). Soil types in the study area are dominated by red earth (Humic Acrisols in the Food and Agriculture Organization [FAO] soil taxonomy, or Ultisols in US soil taxonomy), which was highly weathered from granite and inherently infertile, acidic, nutrient-deficient, poor in organic matter, and low capacity for holding and supplying water (He et al. 2004; Chen et al. 2013).

Delineation of Slope Position Units. Without loss of generality, this study uses a simple system of three types of slope positions (i.e., ridge, backslope, and valley), which has been applied in existing watershed modeling (Arnold et al. 2010; Ajami et al. 2016). In addition, a hierarchical structure of spatial units (i.e., subbasin, hillslope, and slope position) is maintained, so as to support the representation of the spatial relationships between BMPs and slope positions along a hillslope in the spatial BMP optimization.

A gridded DEM with $10 \mathrm{~m}$ resolution of the Youwuzhen watershed was created from a 1:10,000 topographical map with a contour interval of $5 \mathrm{~m}$ by the "Topo To Raster" tool of ArcGIS 10.3 software (Environmental Systems Research Institute, Inc, Redlands, California). Subbasins were delineated based on an accumulated threshold of $0.185 \mathrm{~km}^{2}$ (Chen et al. 2013). For each subbasin, which consists of headwater, left hillslope, and right hillslope (relative to flow direction), hillslopes were then delineated according to the D8 flow direction model (O'Callaghan and Mark 1984). Each hillslope contains slope position units with downstream and upstream relationships.

A prototype-based inference method proposed by Qin et al. (2009) was adopted to derive the fuzzy memberships of each cell to the three slope positions. This method was chosen because it can reasonably perform fuzzy inference on both attribute and spatial domains. Then, a crisp classification map of slope position units in the study area was obtained by a "hardening" process, i.e., applying the maximum membership principle 


\section{Figure 2}

The proposed framework for the spatial optimization of watershed best management practices (BMPs) based on slope position units.

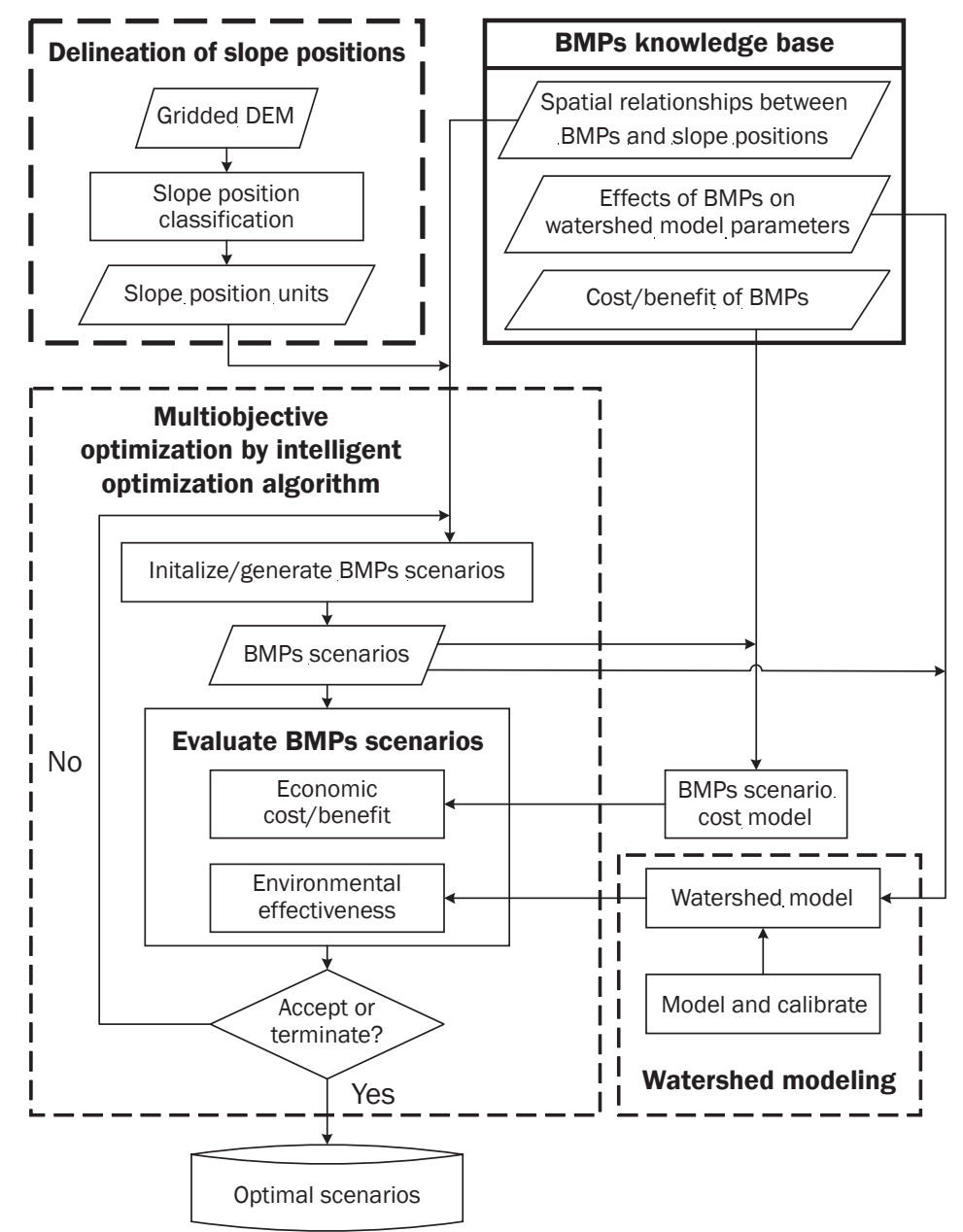

\section{Figure 3}

Map of the Youwuzhen watershed in Fujian Province, China.

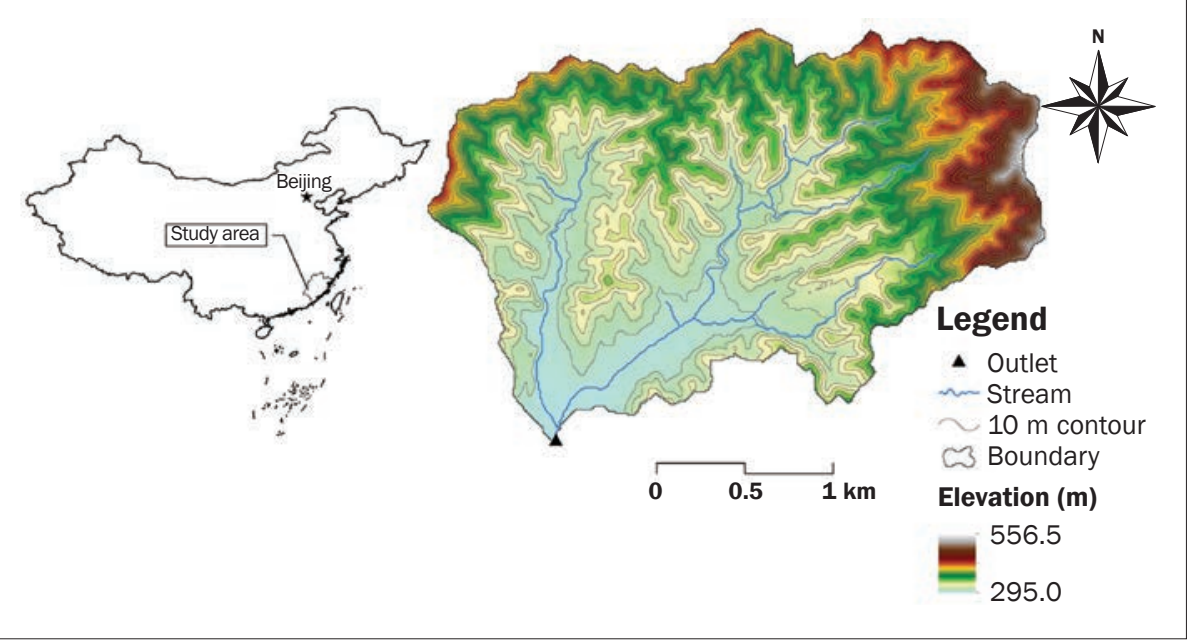

cell-by-cell to all fuzzy membership maps of individual slope position types resulting from the prototype-based inference method (Qin et al. 2009; Zhu et al. 2018). The numbers of subbasin, hillslope, and slope position units delineated in the study area are 17,35 , and 105 , respectively (figure 4).

Watershed Processes Modeling and Calibration. Spatially Explicit Integrated Modeling System (SEIMS), a spatially explicit watershed modeling framework whose original hydrologic model is WetSpa (Water and Energy Transfer between Soil, Plant, and Atmosphere) (Liu et al. 2003; Liu 2004), was selected because of its spatially explicit representation of watershed processes and flexible modular framework for coupling various watershed process modules and scenario analysis (Liu et al. 2014, 2016). SEIMS has been extended to simulate long-term watershed processes including hydrology, soil erosion, and plant growth. The representation of BMPs in SEIMS is implemented through the relative alterations of model parameters, which characterize BMPs' environmental effects in the locations of BMPs' placement (Wu et al. 2018). SEIMS is still under continuous development, and the source code is available on Github (https://github.com/ lreis2415/SEIMS).

The hydrologic processes simulated in this study include interception, surface depressional storage, surface runoff, infiltration, potential evapotranspiration, percolation, interflow, groundwater flow, and channel flow. The interception process is simulated by the maximum canopy storage method proposed by Aston (1979). The depression storage is estimated by an empirical equation suggested by Linsley et al. (1975). Surface runoff and infiltration are estimated using a modified coefficient method, which depends on slope, land use, soil type, soil moisture, and rainfall intensity (Liu 2004). The potential evapotranspiration is estimated by the Priestley-Taylor equation (Priestley and Taylor 1972). The percolation process is simulated using the method in SWAT when the water content of the soil layer exceeds the field capacity and the layer below it is not saturated (Neitsch et al. 2011). Interflow (or shallow subsurface lateral flow) is assumed to occur after percolation and cease when soil moisture is lower than field capacity and is simulated from Darcy's Law and the kinematic approximation (Liu 2004). The groundwater flow is estimated with a linear 


\section{Figure 4}

Slope position units delineated in the Youwuzhen watershed.

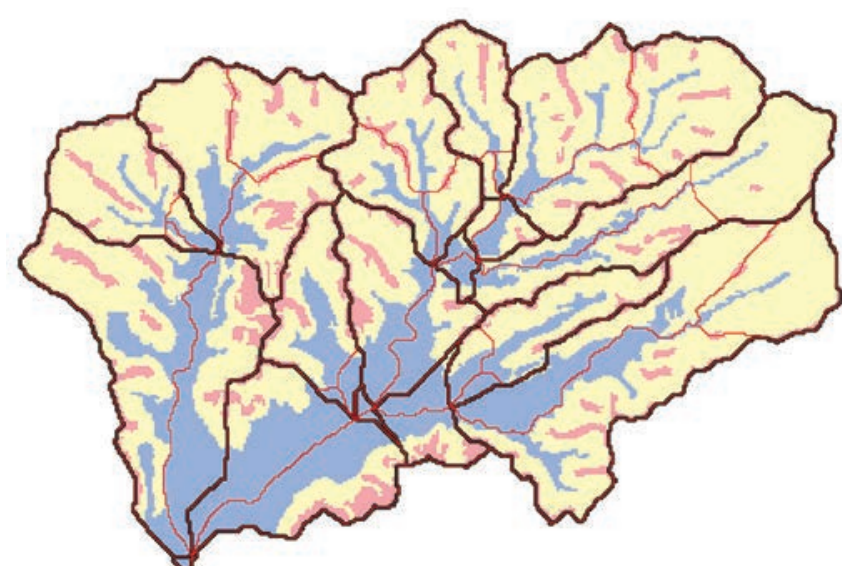

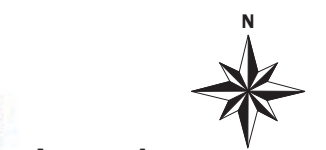

Legend

$\square$ Hillslope units

Subbasin

Slope position units

Ridge

Backslope

Valley

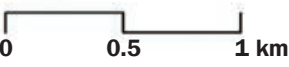

reservoir method as a function of groundwater storage and a recession coefficient on subbasin scale (Liu 2004). The overland flow routing algorithm is adapted from a diffusive transport approach proposed by Liu et al. (2003). The Muskingum method (Cunge $1969)$ is used for channel flow routing.

Sediment yield caused by water erosion is estimated for each cell with the Modified Universal Soil Loss Equation (MUSLE) (Williams 1975) and is routed into channels with surface runoff. A simplified Bagnold stream power equation from Williams (1980) is used for sediment routing in stream channels, in which the maximum amount of sediment that can be transported from a reach segment is a function of the peak channel velocity (Neitsch et al. 2011).

Plant growth process in SEIMS is adapted from the SWAT model, which is a simplified version of Environmental Policy Integrated Climate (EPIC) plant growth model (Williams 1995) and utilizes a single plant growth model to simulate all types of land covers.

The data necessary for watershed modeling and calibration based on SEIMS (i.e., the spatial data such as DEM, soil, land use, and climate data, and site-monitoring data at the watershed outlet) were collected. The land use map was manually interpreted from Advanced Land Observation Satellite (ALOS) image derived in 2009 (Chen et al. 2013). The soil type map was from the Second National Soil Survey of Changting County with a scale of 1:50,000 (Chen et al. 2013). Soil properties such as mechanical composition and organic matter were measured from field samplings (Chen et al. 2013;
Xie et al. 2015). Other soil water characteristics (e.g., soil hydraulic conductivity and field capacity) were calculated with the SoilPlant-Air-Water (SPAW) model (Saxton and Rawls 2006). Soil erodibility factors, cover management factors, and conservation practice factors for the USLE model were drawn from the study in this area by Chen and Zha (2016). Daily meteorological data and precipitation were derived from National Meteorological Information Center of China Meteorological Administration data and the local monitoring station, respectively. The periodic monitoring flow and sediment discharge data at the watershed outlet from 2013 to 2015 were provided by the Soil and Water Conservation Bureau of Changting County, Fujian Province, China.

To calibrate the watershed model for the following spatial optimization of BMPs, we selected those periods with available data and rainstorms that had more than three consecutive days of rainfall and for which there were complete records of runoff generation and sediment yield. As a result, the years of 2013 and 2014 were selected for watershed model calibration, and the year 2015 was selected for validation of the watershed model.

Model performance indicators such as Nash-Sutcliffe efficiency (NSE, equation 1), percentage bias (PBIAS, equation 2), and root mean square error-standard deviation ratio (RSR, equation 3) recommended by Moriasi et al. (2007) were used to evaluate the watershed model:

$N S E=1-\frac{\sum_{i=1}^{n}\left(Y_{i}^{\text {obs }}-Y_{i}^{\text {sim }}\right)^{2}}{\sum_{i=1}^{n}\left(Y_{i}^{\text {obs }}-Y^{\text {mean }}\right)^{2}}$,

$$
\begin{aligned}
& \text { PBIAS }=\frac{\sum_{i=1}^{n}\left(Y_{i}^{\text {obs }}-Y_{i}^{\text {sim }}\right) \times 100}{\sum_{i=1}^{n} Y_{i}^{\text {obs }}} \text {, and } \\
& R S R=\frac{\sqrt{\sum_{i=1}^{n}\left(Y_{i}^{\text {obs }}-Y_{i}^{\text {sim }}\right)^{2}}}{\sqrt{\sum_{i=1}^{n}\left(Y_{i}^{\text {obs }}-Y^{\text {mean }}\right)^{2}}},
\end{aligned}
$$

where $Y_{i}^{\text {obs }}$ and $Y_{i}^{\text {sim }}$ are the $i$ th observed and simulated values, respectively; $Y^{\text {mean }}$ is the average of all observed values; and $n$ is the number of observed values.

The modeling performance of the manually calibrated SEIMS model for flow discharge and sediment export, both in the calibration and validation periods, are shown in figures 5 and 6 , respectively. The calibration of flow has an NSE, RSR, PBIAS, and $R^{2}$ of $0.48,0.72,-16.24 \%$, and 0.58 , respectively (figure $5 \mathrm{a}$ ). According to the general performance ratings for simulations at a monthly time step by Moriasi et al. (2007), the model performance is satisfactory when the model results receive a value of NSE, RSR, and PBIAS better than $0.50,0.70$, and $\pm 25 \%$ (for sediment it is $\pm 55 \%$ ), respectively. Thus, the performance of flow is approximately satisfactory. For sediment, the NSE, RSR, PBIAS, and $R^{2}$ are $0.30,0.85,-58.19 \%$, and 0.37 , respectively (figure 6a). Although the overall simulated trend is consistent with the observed values according to $R^{2}$, the simulation results still overestimated the low values and underestimated the peak sediment exports (figure 6a). This is similar to other cases in which model simulations are generally poorer for shorter time steps than for longer time steps (Engel et al. 2007). The performance of sediment can be regarded as acceptable.

Although the performance statistics for the validation period are poor for flow and sediment (figure $5 \mathrm{~b}$ and figure $6 \mathrm{~b}$ ), the general trends of hydrographs in the study area can still be captured by the calibrated SEIMS model from a visual perspective. This means the calibrated model can be used for the following spatial optimization of BMPs. Therefore, the year 2013 was used as simulation period, and the scenario for model calibration was selected as the baseline scenario. The BMP scenarios generated during the spatial optimization will be evaluated for 2013 by the calibrated SEIMS model. 


\section{Figure 5}

(a) Calibration and (b) validation of the simulated flow discharge (Q) at the watershed outlet of the study area.

(a)

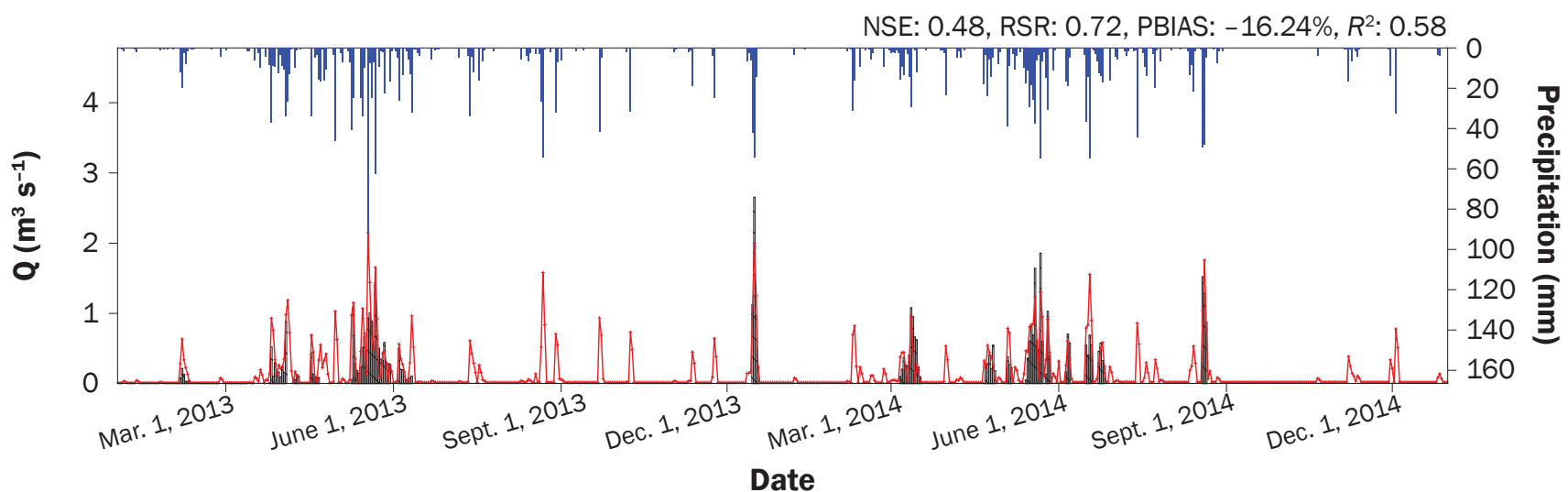

\section{Legend}

Rainfall $\square$ Observation Simulation

(b)

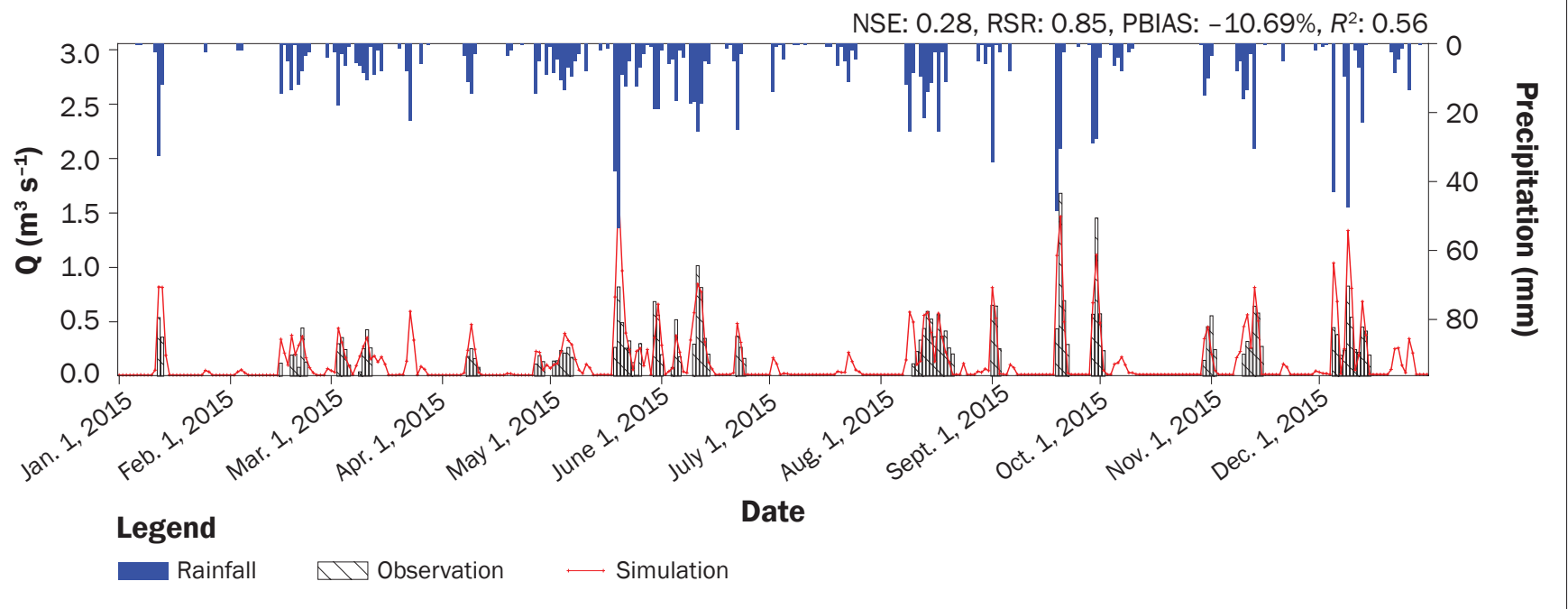

Best Management Practices Knowledge Base. Four BMPs that have been implemented in Changting County for soil and water conservation are considered in this study: closing measures (CM), arborbush-herb mixed plantation (ABHMP), low-quality forest improvement (LQFI), and orchard improvement (OI). Their brief descriptions are listed in table 1 (Chen et al. 2013, 2017).

The BMP knowledge base for this study mainly includes three components: the cost-benefit, the environmental effects, and the spatial relationships between BMPs and slope positions. The first two components are normal components in BMP knowledge bases for existing approaches to spatial BMP optimization, while the third is specific to the proposed approach.
The cost-benefit for each BMP consists of initial implementation cost, annual maintenance cost, and annual benefit estimated from local government project (table 2; Wang 2008).

For evaluating the environmental effects of $\mathrm{BMPs}$ on mitigating soil erosion, the relative improvements of major parameters related to hydrologic and soil erosion processes were collected and are listed in table 3 . Relative changes to the conservation practice factors in the USLE model (i.e., USLE_P) in table 3 were adopted from the calibrated SWAT model in Chen et al. (2013). Other factors were calculated directly (e.g., organic matter, bulk density, and total porosity) or indirectly (e.g., soil hydraulic conductivity and soil erodibility factor of USLE model) from the sample-plot data provided by Fujian Soil and
Water Conservation Monitoring Station et al. (2010). These sample-plot locations were collected from locations where their respective BMPs have been implemented for eight years, and they were compared with control groups retaining their original land uses without the implementation of BMPs.

As stated above, the knowledge of the spatial relationships between the four BMPs and slope positions were formalized as two types of rules for the study area. Rules of the first type, i.e., the suitable BMPs for each type of slope position, are generalized from the description in table 1 and formalized in table 4. Rules of the second type, i.e., the spatial constraint among BMPs on different types of slope position along the hillslope from upstream to downstream, are based on an effectiveness grade, which rep- 


\section{Figure 6}

(a) Calibration and (b) validation of the simulated sediment export (SED) at the watershed outlet of the study area.

(a)

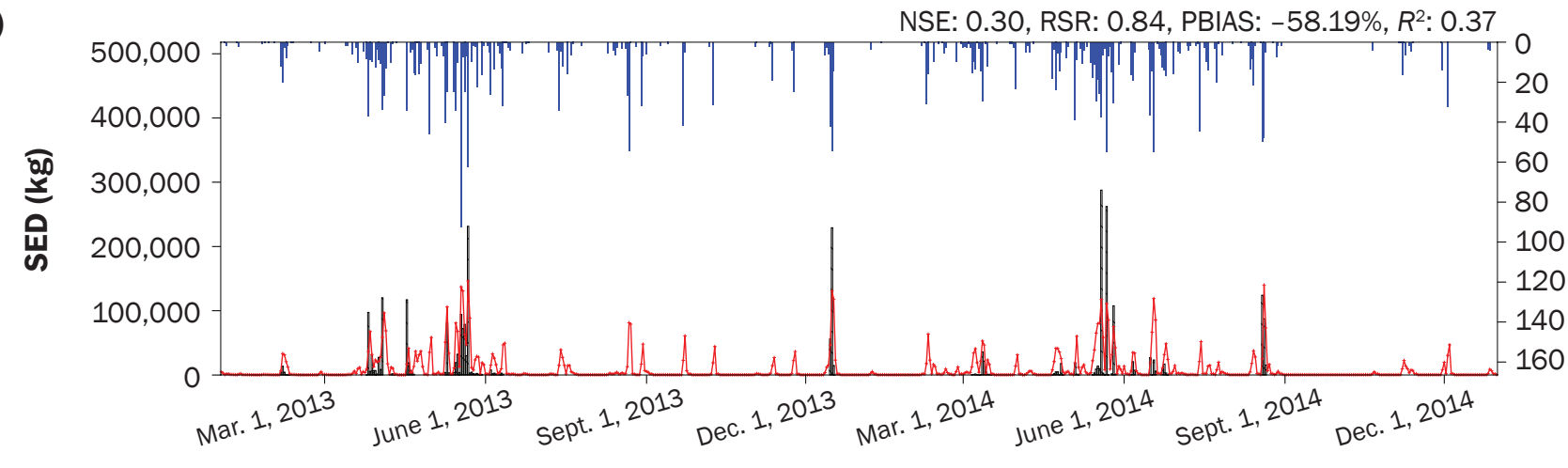
NSE: 0.30, RSR: 0.84, PBIAS: $-58.19 \%, R^{2}: 0.37$

\section{Date}

\section{Legend}

Rainfall $\square$ Observation $\longleftarrow$ Simulation

(b)

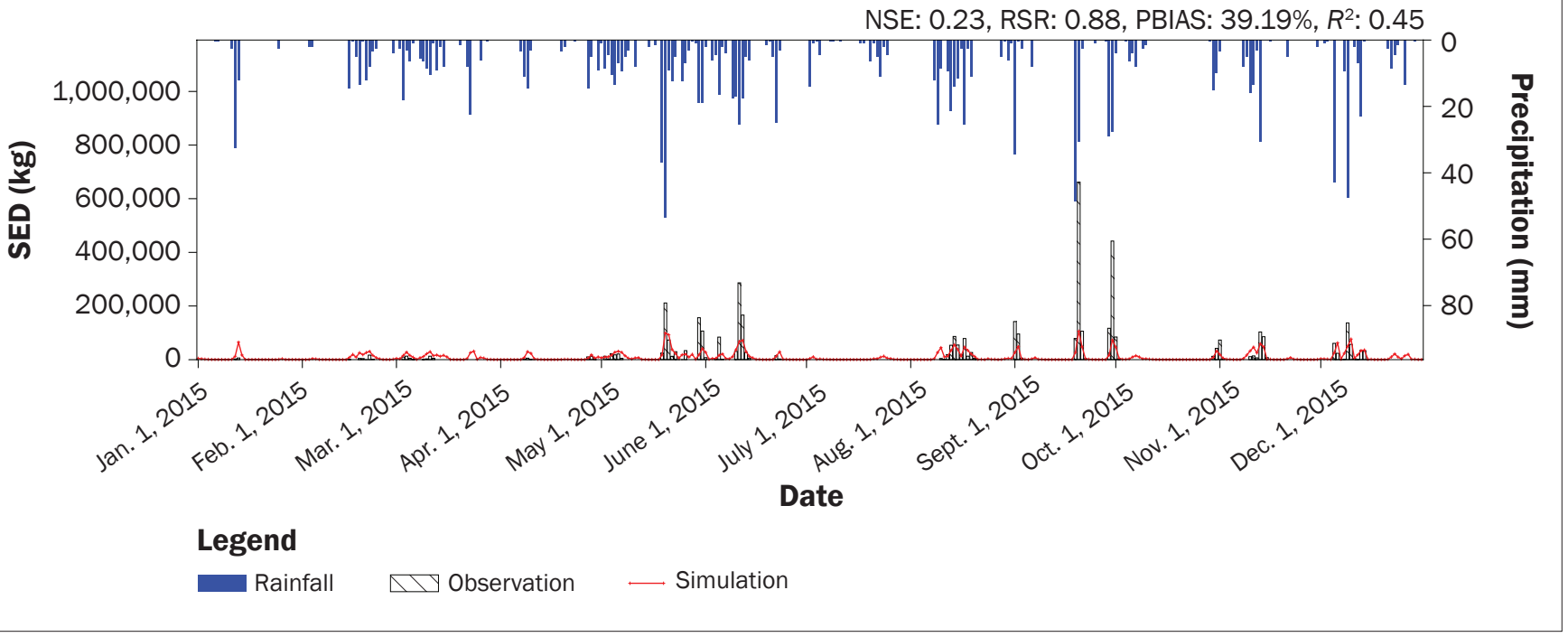

\section{Table 1}

A brief description of four best management practices (BMPs) that have been adopted in Changting County and considered in this study.

\begin{tabular}{|c|c|}
\hline BMP & Brief description \\
\hline Closing measures (CM) & $\begin{array}{l}\text { Facilitate afforestation from human disturbance (e.g., tree felling and grazing). Suitable for the ridge } \\
\text { area and upslope positions that suffer from low or moderate soil erosion. }\end{array}$ \\
\hline Arbor-bush-herb mixed plantation (ABHMP) & $\begin{array}{l}\text { Planting trees (e.g., Schima superba and Liquidambar formosana), bushes (e.g., Lespedeza } \\
\text { bicolor), and herbs (e.g., Paspalum wettsteinii) in level trenches with compound fertilizer in } \\
\text { positions with high-to-violent soil and water losses. Suitable for all slope positions. }\end{array}$ \\
\hline Low-quality forest improvement (LQFI) & $\begin{array}{l}\text { Improving the infertile forest by applying compound fertilizer to every hole }(40 \times 40 \times 40 \mathrm{~cm}) \text { in the } \\
\text { uphill position of crown projection. Suitable for the moderate or serious eroded land in the upslope } \\
\text { and steep backslope positions. }\end{array}$ \\
\hline Orchard improvement (OI) & $\begin{array}{l}\text { Constructing level terraces, drainage ditches, storage ditches, irrigation facilities, and roads; } \\
\text { planting economic fruit; and interplanting grasses and Fabaceae (Leguminosae) plants in orchards } \\
\text { on the middle and downslope positions under better water and fertilizer conditions. }\end{array}$ \\
\hline
\end{tabular}


resents the degree of improvement in the area of mitigating soil erosion (table 4). The effectiveness grades range from 1 to 5 , with higher-numbered grades representing better effectiveness. In the current study, a simple rule is adopted according to local experience (Chen et al. 2013), i.e., the effectiveness grade of the BMP placed on the backslope of a hillslope should be greater than or equal to that of the BMP placed on the ridge of the same hillslope. For example, the effectiveness order of BMP sequences for ridge and backslope of a hillslope should be ABHMPABHMP, CM-ABHMP, and CM-CM, while the solution of ABHMP-CM will be ignored because the effectiveness grade of CM (i.e., 3 ) is less than that of ABHMP (i.e., 5).

Multiobjective Optimization by Intelligent Optimization Algorithm. The Nondominated Sorted Genetic Algorithm (NSGA-II) (Deb et al. 2002) was selected as the intelligent optimization algorithm for the proposed approach. NSGA-II can ensure that the optimization solutions are diverse and well distributed in all objective functions under consideration according to its nondominated sorting and elitism properties (Zitzler and Thiele 1999). NSGA-II has been widely applied to spatial BMP optimization with multiobjectives (e.g., maximum environmental effectiveness and minimum net cost) (Rodriguez et al. 2011; Panagopoulos et al. 2012; Yang and Best 2015).

When the NSGA-II is applied to spatial BMP optimization, an individual of a population corresponds to a BMP scenario and is represented as a chromosome with genes as variables (i.e., BMP configuration units with selected BMP type or without BMP). The execution of NSGA-II includes an initialization process of initializing a population of individuals and then a circular process of evaluation and generation of BMP scenarios. For each round (or, equivalently, generation) of the process, the fitness of each individual in the current population is evaluated by objective functions (e.g., environmental effectiveness based on the calibrated watershed model, and economic benefit calculation by BMPs cost model). In the following selection process, the fittest individuals are selected (i.e., duplicated for next round), and those weak individuals are discarded from the population. Those selected individuals are stored as an elite set, which is known as near Pareto optimal solutions (Deb et al. 2002) and will be updated by successive

Table 2

Cost-benefits of four best management practices (BMPs) estimated from local government project (Wang 2008).

\begin{tabular}{lccc}
\hline BMP & $\begin{array}{l}\text { Implementation cost } \\
\text { (CN¥10,000 } \mathbf{~ m}^{-2} \text { ) }\end{array}$ & $\begin{array}{l}\text { Annual maintenance cost } \\
\left.\text { (CN } ¥ \mathbf{1 0 , 0 0 0} \mathbf{~ k m}^{-2}\right)\end{array}$ & $\begin{array}{l}\text { Annual benefit } \\
\left(\mathbf{C N} ¥ \mathbf{1 0 , 0 0 0} \mathbf{~ k m}^{-2}\right)\end{array}$ \\
\hline CM & 15.5 & 1.5 & 2.0 \\
ABHMP & 87.5 & 1.5 & 6.9 \\
LQFI & 45.5 & 1.5 & 3.9 \\
OI & 420.0 & 20.0 & 60.3 \\
\hline
\end{tabular}

Notes: $\mathrm{CM}=$ closing measures. $\mathrm{ABHMP}=$ arbor-bush-herb mixed plantation. $\mathrm{LQFI}=$ low-quality forest improvement. $\mathrm{OI}=$ orchard improvement.

\section{Table 3}

Effects of four best management practices (BMPs) on major soil properties and universal soil loss equation (USLE) factors after eight years of implementation, according to the sample data in Changting County.

\begin{tabular}{lllllll}
\hline BMP & OM* & BD & PORO† & SOL_K & USLE_K & USLE_P \\
\hline CM & 1.22 & 0.98 & 1.02 & 0.81 & 1.01 & 0.90 \\
ABHMP & 1.45 & 0.93 & 1.07 & 1.81 & 0.82 & 0.50 \\
LQFI & 1.05 & 0.87 & 1.13 & 1.71 & 0.81 & 0.50 \\
OI & 2.05 & 0.96 & 1.03 & 1.63 & 0.88 & 0.75 \\
\hline
\end{tabular}

Notes: Values in table are relative changes (i.e., multiply) corresponding to the original properties. $\mathrm{CM}=$ closing measures. $\mathrm{ABHMP}=$ arbor-bush-herb mixed plantation. LQFI = low-quality forest improvement. $\mathrm{OI}=$ orchard improvement. $\mathrm{OM}=$ organic matter. $\mathrm{BD}=$ bulk density. $\mathrm{PORO}$ $=$ total porosity. SOL_K = soil hydraulic conductivity. USLE_K = soil erodibility factor. USLE_P = conservation practice factor.

*The effect on organic matter is the same as on soil organic carbon (C).

†The effect on total porosity is the same as on field capacity, wilting point, etc.

Table 4

The knowledge on the spatial relationships between best management practices (BMPs) and slope positions.

\begin{tabular}{llll}
\hline BMP & Suitable slope positions & Suitable land uses & Effectiveness grade \\
\hline CM & Ridge, backslope & Forest & 3 \\
ABHMP & Ridge, backslope, and valley & Forest, orchard & 5 \\
LQFI & Backslope & Forest & 4 \\
OI & Valley & Forest, orchard & 4 \\
\hline
\end{tabular}

Notes: $\mathrm{CM}=$ closing measures. $\mathrm{ABHMP}=$ arbor-bush-herb mixed plantation. $\mathrm{LQFI}=$ low-quality forest improvement. $\mathrm{OI}=$ orchard improvement.

generations. The offspring are generated by crossover and mutation operators (or, equivalently, regeneration), and then are added to the population for next round of evaluation. This process is repeated until a given maximum generation number has been reached.

When the NSGA-II is adopted by the proposed approach to spatial BMP optimization, the spatial relationships between BMPs and slope positions along the hillslopes are incorporated into the initialization and regeneration (i.e., crossover and mutation) of BMP scenarios. In the initialization pro- cess, the valley unit of each hillslope is first randomly allocated one suitable BMP or left without a BMP. Then, an iteration procedure is performed to select and allocate BMPs for other slope position units in an upstream-downstream order (i.e., backslope and ridge by sequence) based on the rules of spatial relationships between BMPs and slope positions along the hillslope. In the regeneration process, every BMP scenario generated after crossover and mutation operations is adjusted according to the rules of spatial relationships between BMPs and slope positions. 
In such a way, every BMP scenario evaluated in the spatial BMP optimization is reasonable in terms of the spatial relationships between BMPs and slope positions, which means that the same will be true of every optimal BMP scenario. Unreasonable BMP scenarios will not be considered, which results in higher optimization efficiency.

The multiobjectives in this study are maximizing the reduction rate of soil erosion and minimizing the net cost of BMPs (equation 4). The calibrated SEIMS model for the Youwuzhen watershed is used to evaluate the reduction rate of soil erosion from each BMP scenario in comparison to a baseline scenario (equation 5). A simple BMP cost model (equation 6) is used to calculate the net cost of each BMP scenario according to the cost-benefit knowledge in the BMP knowledge base. The following three equations are used:

$\min \left\{[f(X)]^{\wedge}[-g(X)]\right\}$,

where $X$ represents a BMP scenario; $f(X)$ is the reduction rate of soil erosion under $X$ compared to that under the baseline scenario (equation 5); and $g(X)$ is the net cost of $X$ (equation 6);

$f(X)=\frac{v(0)-v(X)}{v(0)}$; and

$g(X)=\sum_{i=1}^{n} A\left(x_{i}\right) \times\left\{\left[C\left(x_{i}\right)+y r \times\left(M\left(x_{i}\right)-B\left(x_{i}\right)\right)\right]\right\}$,

where $v(0)$ and $v(X)$ are the total amounts of soil erosion $(\mathrm{kg})$ under baseline scenario and the $X$ scenario, respectively; $n$ is the number of BMP configuration units (slope position units); $A\left(x_{i}\right)$ is the area covered by the BMP implemented in the ith configuration unit; $y r$ is the years since the BMP was implemented, which is eight in this study (table 3); and $C\left(x_{i}\right), M\left(x_{i}\right)$, and $B\left(x_{i}\right)$ are unit costs for initial implementation, annual maintenance, and annual benefit (table 2), respectively.

Experimental Design. The effectiveness of the proposed approach was compared with the traditional approach to spatial BMP optimization (hereafter referred to as the random approach), which initializes and generates individuals by selecting and allocating BMPs on genes (corresponding to BMP configuration units, i.e., slope position units in this study) randomly.

The proposed approach and the random approach were implemented based on a
Python framework for evolutionary computation known as DEAP (Fortin et al. 2012). SCOOP (Hold-Geoffroy et al. 2014) was incorporated to improve computation efficiency by distributing tasks dynamically across Linux cluster. Thus, the experiment was conducted on a Linux cluster, which consists of one management node and four computation nodes. Each node has two Intel Xeon E5645 central processing units (CPUs) and each CPU has six cores.

In the evaluation experiment, the main parameter settings of NSGA-II are the same for both approaches. The initial population size is 60 with a selection rate of 0.8 and a maximum generation number of 100 . The crossover probability and the mutation probability are 0.75 and 0.15 , respectively.

The proposed approach was evaluated with respect to two aspects - the quality of near Pareto optimal solutions and the computational efficiency. The quality of near Pareto optimal solutions was evaluated via three methods. The first is visual interpretation of the convergence and diversity of near Pareto optimal solutions derived from all generations. The second is based on the hypervolume index (Zitzler and Thiele 1999), which measures the volume (area for two-dimensions) of objective space covered by a set of near Pareto optimal solutions. A higher hypervolume index indicates a better quality of solutions. The change of the hypervolume index with generations can provide a quantitative comparison of the quality of near Pareto optimal solutions considering both convergence and diversity (Zitzler et al. 2003). In this study, the reference point for calculating the hypervolume index is $(300$, $-1)$, which represents the economic benefit being CN $¥ 300$ million (1 Yuan $=$ US\$0.16) and the reduction rate of soil erosion being -1 . Note that both the hypervolume index and near Pareto optimal front represent evaluations from a mathematical perspective and have less practical meaning than the spatial configuration of BMP scenarios when it comes to decision making for watershed management. Therefore, the third method is to discuss the rationality of the spatial configurations of examples selected from the near Pareto optimal solutions.

\section{Results and Discussion}

Near Pareto Optimal Solutions Derived from All Generations. Figure 7 shows the near Pareto optimal solutions derived from all generations by the proposed approach and the random approach. From the visual interpretation, the proposed approach shows a better convergence and a similar diversity in the Pareto optimal front, compared to the random approach (figure 7). During the spatial optimization, the calibrated SEIMS model for the Youwuzhen watershed was executed to evaluate 1,476 BMP scenarios for the proposed approach and 1,523 BMP scenarios for the random approach, while the total runtimes were 8.7 and 11.8 hours, respectively. This means that with the constraint of the relationships between BMPs and slope positions, the proposed approach can reduce the search space of optimal solutions, and hence improve the computational efficiency (Maier et al. 2014).

The Change of Hypervolume Index with Generations. The change of the hypervolume index with generations (figure 8) shows that the proposed approach has an obvious advantage over the random approach when the generation number is less than 35 , especially in the first 10 generations (figures $9 \mathrm{a}$ and 9b). With the increase of generation number, the hypervolume index values from the two approaches were similar until the random approach produced steadily higher values of the hypervolume index after the 65th generation.

This effect might be a result of the fact that the search space for the proposed approach is constrained by the BMP knowledge base, and thus is a subset of the search space for the random approach. Therefore, the proposed approach can lead individuals (i.e., BMP scenarios) to the ideal Pareto optimal front more rapidly than the random approach at the early phase of optimization (figures $9 \mathrm{a}$ and $9 \mathrm{~b}$ ). This result also suggested that it can be effective to utilize the rules of spatial relationships between BMPs and slope positions as a priori knowledge to achieve better solutions during optimization (Bi et al. 2015; Wu et al. 2018). In the late phase of the optimization, the random approach can generate scenarios beyond the search space of the proposed approach and could reach a higher hypervolume index value (figures 8 and $9 \mathrm{~d}$ ). This phenomenon is common in similar comparison studies, such as Pyo et al. (2017). Although this means a better set of near Pareto optimal solutions from the mathematical perspective, the scenarios in this set might not be practical in terms of their spa- 


\section{Figure 7}

Near Pareto optimal solutions derived from the first to 10oth generation by (a) the proposed approach and (b) the random approach.

(a)

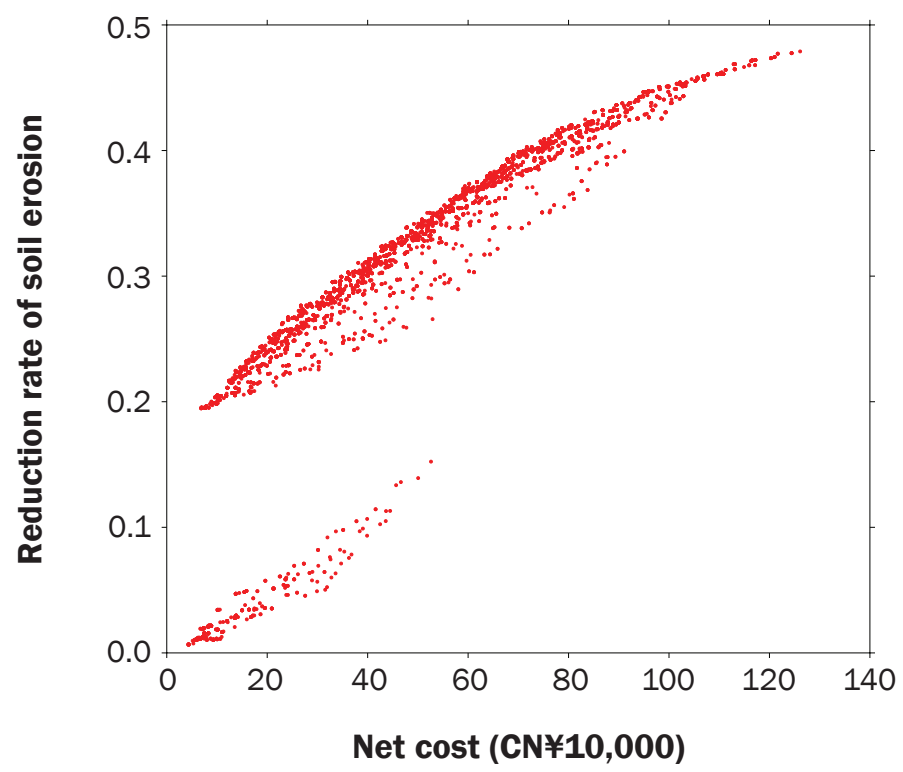

(b)

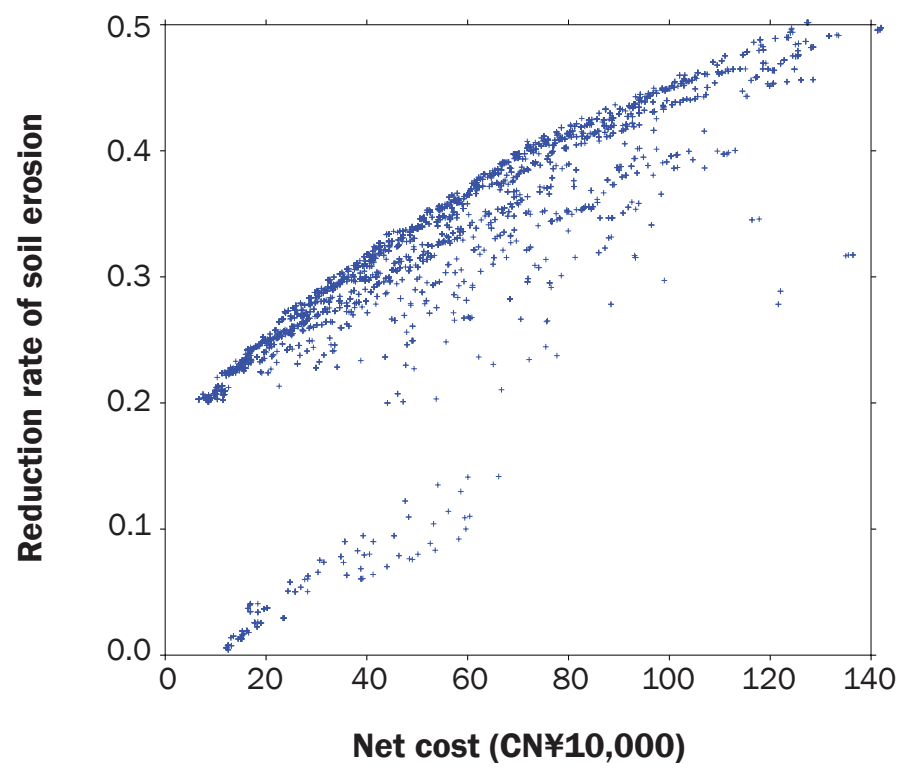

tial configurations of BMPs, as discussed in the following section.

Spatial Configuration of Selected Best Management Practice Scenarios. BMP scenarios from each approach with similar economic effectiveness (i.e., CN¥0.5 million net cost) were randomly selected from the near Pareto optimal solutions of the 10th generation (figure 9b) and mapped as figure 10. The BMP scenario from the proposed approach could achieve a $32.4 \%$ reduction rate of soil erosion while that from the random approach could achieve $21.2 \%$. In the BMP scenario shown in figure $10 \mathrm{a}$, the BMPs allocated by the proposed approach are mainly CM and ABHMP, and are distributed mainly on ridges and backslopes. This matches the relationships between BMPs and slope positions. However, in the BMP scenario from the random approach (figure $10 \mathrm{~b})$, there are several inappropriate allocations violating the relationships between
BMPs and slope positions, e.g., allocating OI on ridges and CM on valleys. These inappropriate allocations make this BMP scenario unreasonable for practical engineering. Thus, in the 10th generation at the early phase of optimization, the proposed approach can derive more practicable and effective optimal BMP scenarios than the random approach.

Another two BMP scenarios from the proposed approach and the random approach with similar environmental effectiveness (i.e., $48 \%$ reduction rate of soil erosion) were randomly selected from the near Pareto optimal solutions of the 100th generation (figure $9 \mathrm{~d})$ and mapped in figure 11. The net cost of the scenario from the proposed approach (i.e., CN¥1.22 million; figure 11a) would be higher than the cost of the scenario from the random approach (i.e., CN¥1.15 million; figure $11 \mathrm{~b})$. From the mathematical view, the random method generates a more optimal solution than the proposed approach. However, the spatial BMP configuration of the scenario from the random approach still shows several inappropriate allocations that violate the relationships between BMPs and slope positions, which means that it is impractical for watershed management.

\section{Summary and Conclusions}

This paper proposes a spatial optimization approach to watershed BMPs based on slope position units. In the proposed approach, slope position units, as homogeneous spatial units with physical geographic features, are used as BMP configuration units by which the spatial relationships between BMPs and slope positions can be explicitly considered in spatial BMP optimization.

The proposed approach was combined with a spatially distributed and physically based watershed model (i.e., SEIMS) and a genetic algorithm (i.e., NSGA-II) as applied to a small watershed for spatial BMP optimization with the multiobjectives of maximizing the reduction ratio of soil erosion and minimizing the net cost of the BMP scenario. Experimental results show that the proposed approach is effective and efficient at proposing practicable BMP scenarios for integrated watershed management, when compared to the random approach.

The proposed spatial optimization approach to watershed BMPs based on slope position units can be easily combined with other watershed models (e.g., SWAT+ [Bieger et al. 2016]), intelligent optimization algorithms 


\section{Figure 8 \\ Changes in the hypervolume index with generations by the proposed approach and the random approach, respectively.}

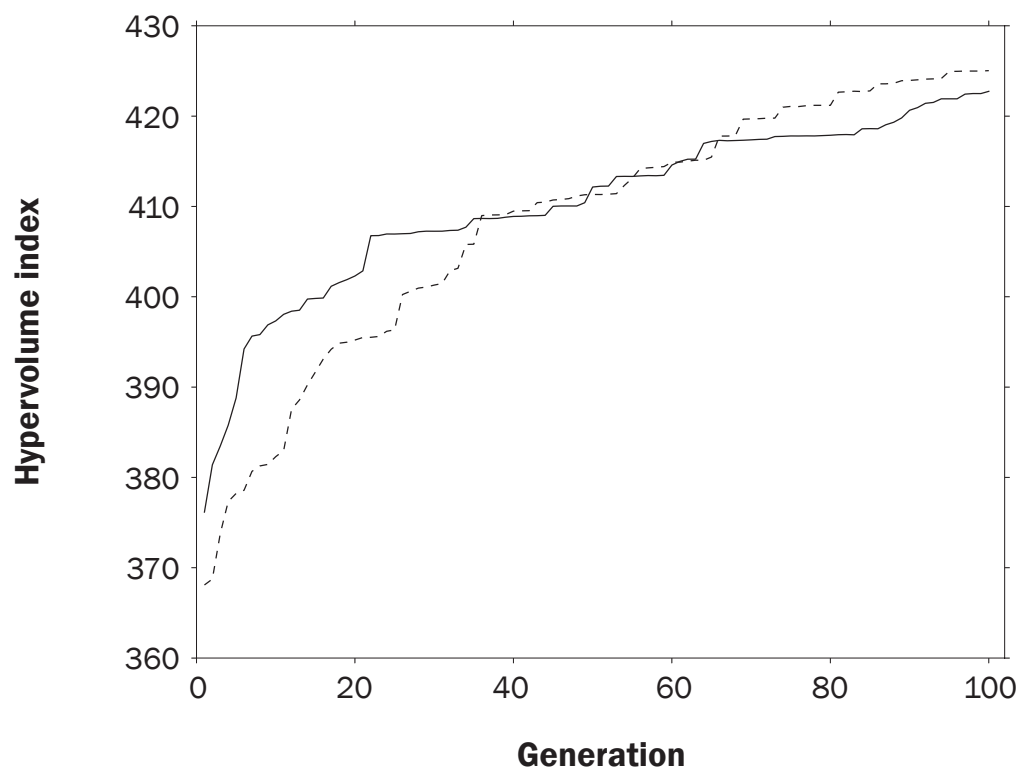

Legend

- The proposed approach _ - - The random approach

(e.g., SPEA2 [Zitzler et al. 2001]), slope positions systems (e.g., five slope positions used in Qin et al. [2009] and Zhu et al. [2018]), and other BMPs available for different study areas.

This study also raises the following study issues for future work: (1) comparison with the adoption of other spatial BMP configuration units; and (2) improvement of the intelligent optimization algorithm to accelerate the evolution of Pareto optimal solutions, especially for large watersheds with high numbers of slope position units and many BMPs under consideration.

\section{Acknowledgements}

This study was funded by the National Key Technology R\&D Program (No. 2013BAC08B03-4), the Natural Science Foundation of China (No. 41422109, 41431177, 41601413, 41701520), the Innovation Project of the State Key Laboratory of Resources and Environmental Information System (No. O88RA20CYA), and Natural Science Foundation of Jiangsu Province of China (No. BK20150975). Support to A-X. Zhu from the Vilas Associate Award, the Hammel Faculty Fellow Award, the Manasse Chair Professorship from the University of Wisconsin-Madison, and the "One-Thousand Talents" Program of China is greatly appreciated. We thank the Soil and Water Conservation Bureau of Changting County and its director, Shaoyun Peng, for kindly providing observation data and convenience for our field work.

\section{References}

Ajami, H., U. Khan, N.K. Tuteja, and A. Sharma. 2016. Development of a computationally efficient semidistributed hydrologic modeling application for soil moisture, lateral flow and runoff simulation. Environmental Modelling and Software 85(November):319-331.

Arabi, M., R.S. Govindaraju, M.M. Hantush, and B.A. Engel. 2006. Role of watershed subdivision on modeling the effectiveness of best management practices with SWAT. Journal of the American Water Resources Association 42(2):513-528.

Arnold, J.G., P.M. Allen, M. Volk, J.R. Williams, and D.D. Bosch. 2010. Assessment of different representations of spatial variability on SWAT model performance. Transactions of the American Society of Agricultural and Biological Engineers 53(5):1433-1443.

Arnold, J.G., R. Srinivasan, R.S. Muttiah, and J.R. Williams. 1998. Large area hydrologic modeling and assessment part I: Model development. Journal of the American Water Resources Association 34(1):73-89.

Aston, A. 1979. Rainfall interception by eight small trees. Journal of Hydrology 42(3):383-396.

Band, L. 1999. Spatial hydrography and landforms. In GIS: Management Issues and Applications, ed. P. Longley, M. Goodchild, D. Maguire, and D. Rhind, 527-542. Hoboken, NJ: John Wiley \& Sons.

Berry, J.K., J.A. Delgado, F.J. Pierce, and R. Khosla. 2005. Applying spatial analysis for precision conservation across the landscape. Journal of Soil and Water Conservation 60(6):363-370.

Bi, W., G.C. Dandy, and H.R. Maier. 2015. Improved genetic algorithm optimization of water distribution system design by incorporating domain knowledge. Environmental Modelling and Software 69(July):370-381.

Bieger, K., J.G. Arnold, H. Rathjens, M.J. White, D.D. Bosch, P.M.Allen, M.Volk, and R. Srinivasan. 2016. Introduction to SWAT+, a completely restructured version of the Soil and Water Assessment Tool. Journal of the American Water Resources Association 53(1):115-130.

Bosch, D.D., C.C. Truman, T.L. Potter, L.T. West, T.C. Strickland, and R.K. Hubbard. 2012. Tillage and slope position impact on field-scale hydrologic processes in the South Atlantic Coastal Plain. Agricultural Water Management 111(August):40-52.

Cai, Q.G., A.X. Zhu, H.X. Bi, and L.Y. Sun. 2012. Paradigms for integrated soil and water conservation over main water erosions in China. Beijing: China Water Power Press (in Chinese).

Chang, C.L., P.T. Chiueh, and S.L. Lo. 2007. Effect of spatial variability of storm on the optimal placement of best management practices (BMPs). Environmental Monitoring and Assessment 135(December):383-389.

Chen, Z.Q., Z.B. Chen, L.Y. Bai, and Y. Zeng. 2017. A catastrophe model to assess soil restoration under ecological restoration in the red soil hilly region of China. Pedosphere 27(4):778-787.

Chen, Z.B., Z.Q. Chen, and H. Yue. 2013. Comprehensive research on soil and water conservation in granite red soil region: A case study of Zhuxi watershed, Changting County, Fujian province. Beijing: Science Press (in Chinese).

Chen, S.F., and X. Zha. 2016. Evaluation of soil erosion vulnerability in the Zhuxi watershed, Fujian Province, China. Natural Hazards 82(3):1589-1607.

Chichakly, K.J., W.B. Bowden, and M.J. Eppstein. 2013. Minimization of cost, sediment load, and sensitivity to climate change in a watershed management application. Environmental Modelling and Software 50(December):158-168.

Cunge, J.A. 1969. On the subject of a flood propagation computation method (Muskingum method). Journal of Hydraulic Research 7(2):205-230.

Deb, K., A. Pratap, S. Agarwal, and T. Meyarivan. 2002. A fast and elitist multiobjective genetic algorithm: NSGA-II. IEEE Transactions on Evolutionary Computation 6(2):182-197.

Duinker, P.N., and L.A. Greig. 2007. Scenario analysis in environmental impact assessment: Improving explorations of the future. Environmental Impact Assessment Review 27(3):206-219.

Engel, B., D. Storm, M. White, J. Arnold, and M. Arabi. 2007. A hydrologic/water quality model application. Journal of the American Water Resources Association 43(5):1223-1236.

Fortin, F.A., F.M. DeRainville, M.A. Gardner, M. Parizeau, and C. Gagné. 2012. DEAP: Evolutionary algorithms made easy. Journal of Machine Learning Research 13(July):2171-2175.

Fujian Soil and Water Conservation Monitoring Station, Fujian Agriculture and Forestry University, Fujian Normal University, and Changting Soil and Water Conservation Monitoring Station. 2010. Monitoring report of soil and water loss in Changting County. Fuzhou, Fujian, China (in Chinese). 


\section{Figure 9}

Comparison of near Pareto optimal solutions by the proposed approach and the random approach under different generations: (a) the first generation, (b) the 1oth generation, (c) the 35th generation, and (d) the 10oth generation.

(a)

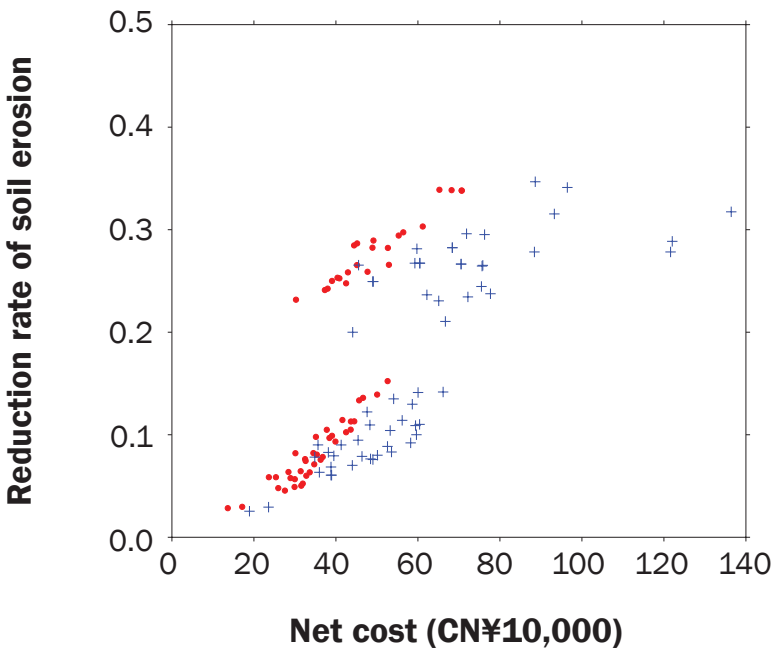

(c)

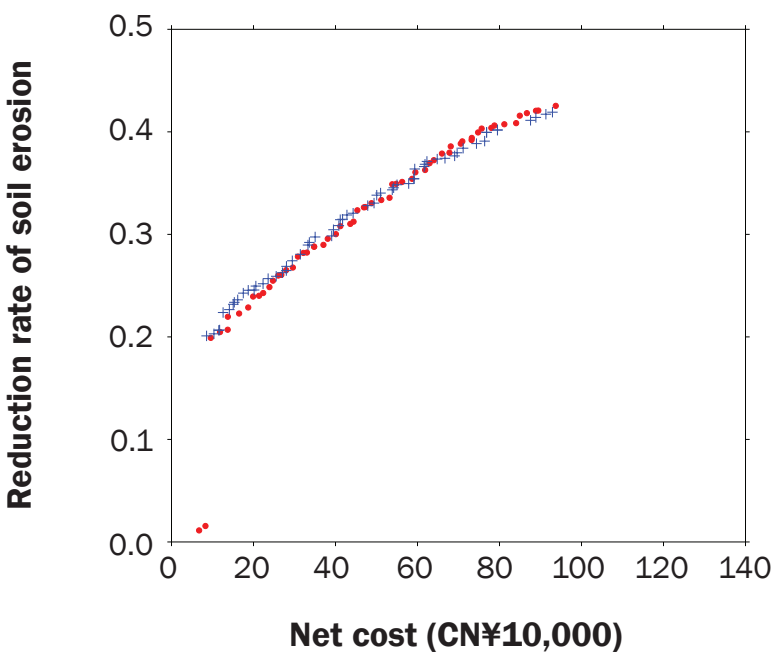

(b)

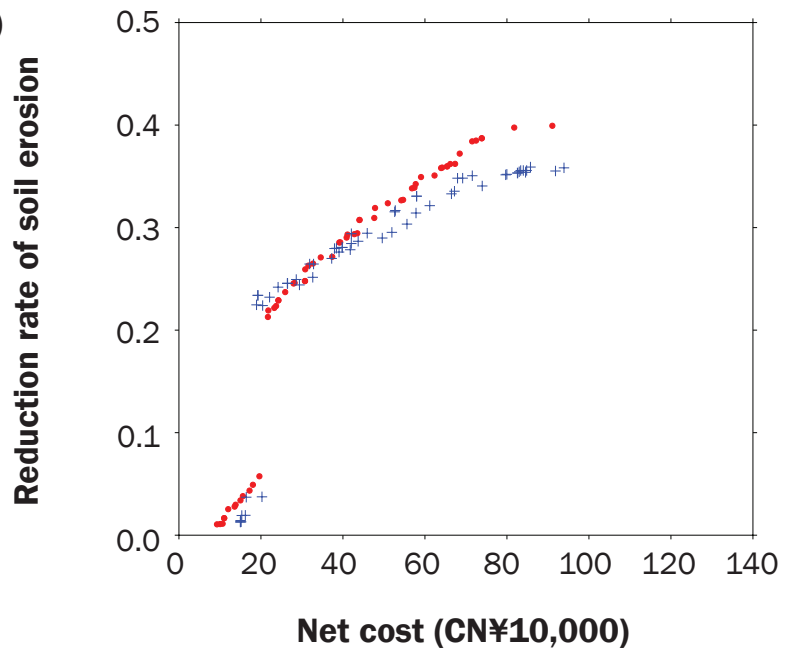

(d)

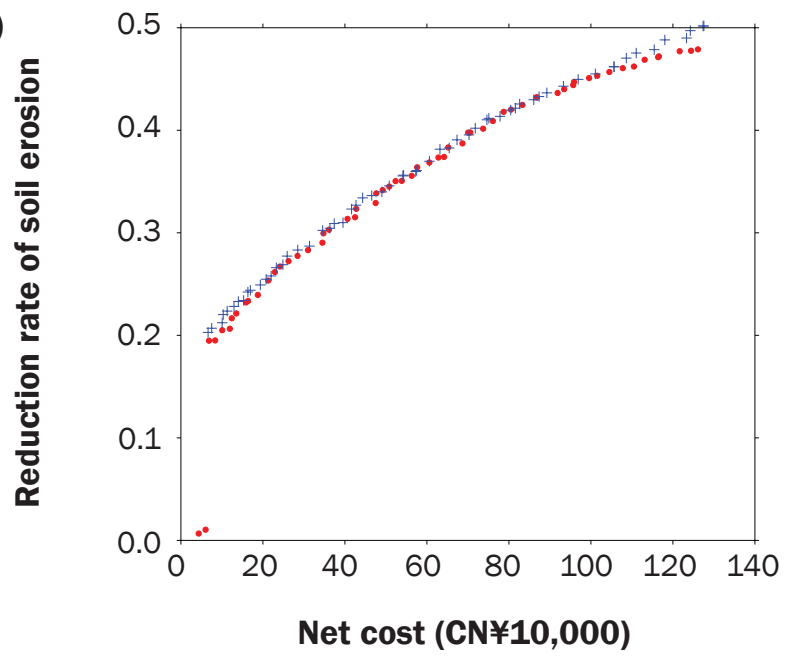

Legend

- The proposed approach $\quad+++$ The random approach

Gaddis, E.J.B., A. Voinov, R. Seppelt, and D.M. Rizzo. 2014 Spatial optimization of best management practices to attain water quality targets. Water Resources Management 28(6):1485-1499

Geng, R., G.H. Zhang, Q.H. Ma, and H.Wang. 2017. Effects of landscape positions on soil resistance to rill erosion in a small catchment on the Loess Plateau. Biosystems Engineering 160(August):95-108.

Gitau, M.W., T.L. Veith, and W.J. Gburek. 2004. Farm-level optimization of BMP placement for cost-effective pollution reduction. Transactions of the American Society of Agricultural Engineers 47(6):1923-1931.

Goddard, T.W. 2005. An overview of precision conservation in Canada. Journal of Soil and Water Conservation 60(6):456-461.

He, Z.L., M.K. Zhang, and M.J. Wilson. 2004. Distribution and classification of red soils in China. In The Red Soils of China:Their Nature, Management and Etilization, ed. M.J. Wilson, Z.L. He, and X.E. Yang, 29-33. Norwell, MA: Kluwer Academic Publishers.

Heathwaite, L., A. Sharpley, and W. Gburek. 2000. A conceptual approach for integrating phosphorus and nitrogen management at watershed scales. Journal of Environmental Quality 29(1):158-166.

Hernandez-Santana, V., X. Zhou, M.J. Helmers, H Asbjornsen, R. Kolka, and M. Tomer. 2013. Native prairie filter strips reduce runoff from hillslopes under annual row-crop systems in Iowa, USA. Journal of Hydrology 477(January):94-103.

Hold-Geoffroy, Y., O. Gagnon, and M. Parizeau. 2014. Once you SCOOP, no need to fork. In Proceedings of the 2014 Annual Conference on Extreme Science and Engineering Discovery Environment, Atlanta, GA, July 13-18, 2014. New York, NY: Association for Computing Machinery.
Jiang, P., S.H. Anderson, N.R. Kitchen, E.J. Sadler, and K.A. Sudduth. 2007. Landscape and conservation management effects on hydraulic properties of a claypan-soil toposequence. Soil Science Society of America Journal 71(3):803-811.

Kalcic, M.M., I. Chaubey, and J. Frankenberger. 2015a. Defining Soil and Water Assessment Tool (SWAT) hydrologic response units (HRUs) by field boundaries. International Journal of Agricultural and Biological Engineering 8(3):69-80.

Kalcic, M.M., J. Frankenberger, and I. Chaubey. 2015b. Spatia optimization of six conservation practices using SWAT in tile-drained agricultural watersheds. Journal of the American Water Resources Association 51(4):956-972.

Linsley, R.K., M.A. Kohler, and J.L.H. Paulhus. 1975 Hydrology for Engineers, 2nd edition. New York: McGraw-Hill. 


\section{Figure 10}

Comparison of the best management practice (BMP) scenarios selected randomly from the near Pareto optimal solutions of the 1oth generation from (a) the proposed approach (32.4\% reduction rate of soil erosion and $C N ¥ 0.51$ million net cost) and (b) the random approach ( $21.2 \%$ reduction rate of soil erosion and $C N ¥ 0.53$ million net cost). $C M$ is closing measures, ABHMP is arbor-bushherb mixed plantation, LQFI is low-quality forest improvement, and $\mathrm{OI}$ is orchard improvement.

(a)

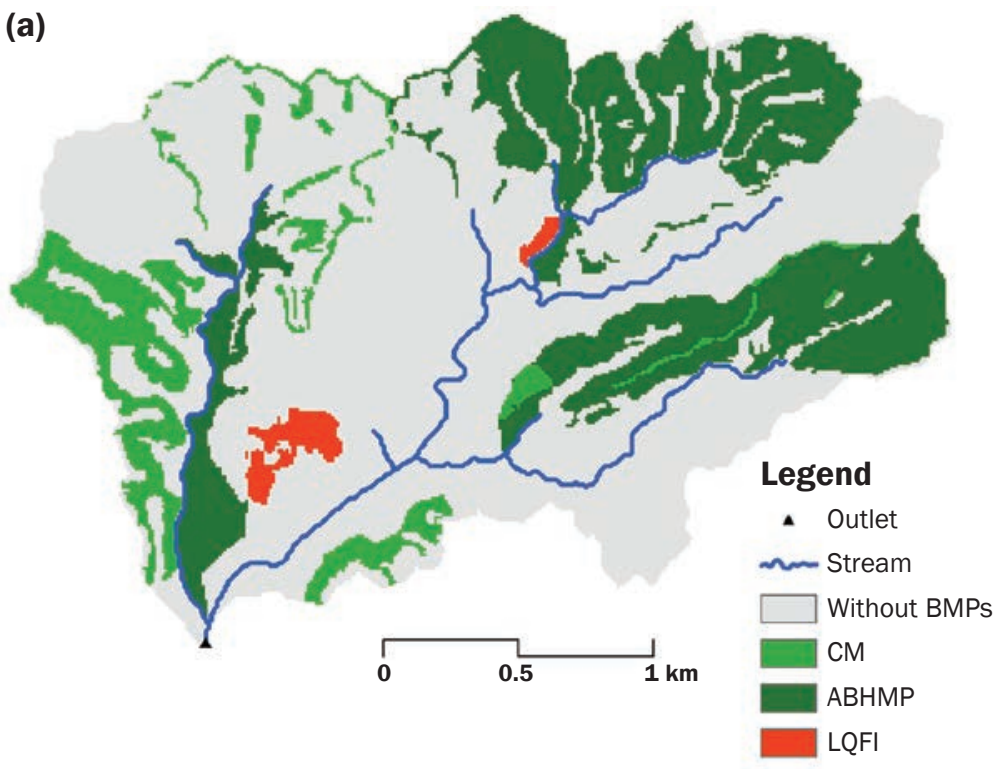

(b)

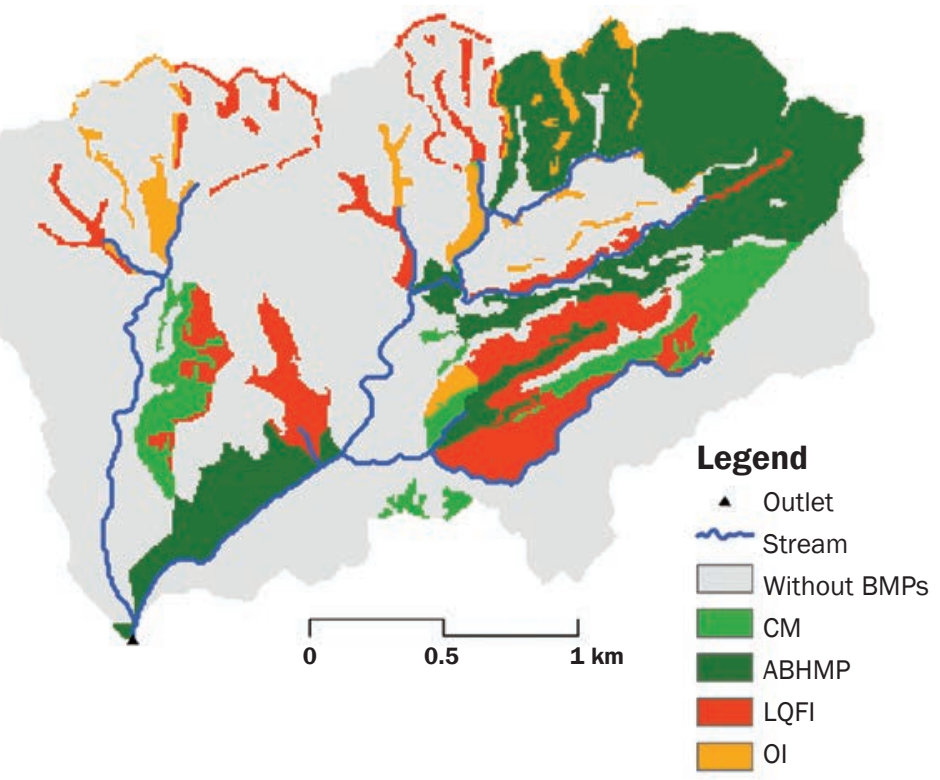

Liu,Y.B. 2004. Development and application of a GIS-based distributed hydrological model for flood prediction and watershed management. PhD dissertation, Vrije Universiteit Brussel, Belgium.

Liu, Y.B., S. Gebremeskel, F. DeSmedt, L. Hoffmann, and L. Pfister. 2003. A diffusive transport approach for flow routing in GIS-based flood modeling. Journal of Hydrology 283(1-4):91-106.

Liu, J.Z., A.X. Zhu, Y.B. Liu, T.X. Zhu, and C.Z. Qin. 2014. A layered approach to parallel computing for spatially
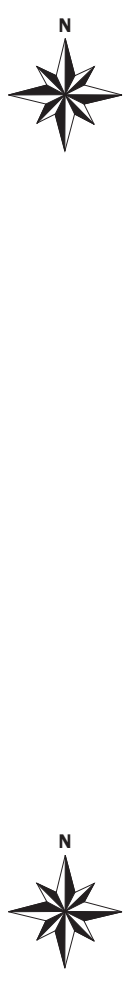

distributed hydrological modeling. Environmental Modelling and Software 51(January):221-227.

Pasha, A. Castelletti, M. Giuliani, and P.M. Reed. 2014. Evolutionary algorithms and other metaheuristics in water resources: Current status, research challenges and future directions. Environmental Modelling and Software 62(December):271-299.

Maringanti, C., I. Chaubey, M. Arabi, and B. Engel. 2011. Application of a multi-objective optimization method to provide least cost alternatives for NPS pollution control. Environmental Management 48(3):448-461.

Miller, B.A., and R.J. Schaetzl. 2015. Digital classification of hillslope position. Soil Science Society of America Journal 79(January):132-145.

Moriasi, D.N., J.G. Arnold, M.W. Van Liew, R.L. Bingner, R.D. Harmel, and T.L. Veith. 2007. Model evaluation guidelines for systematic quantification of accuracy in watershed simulations. Transactions of the American Society of Agricultural and Biological Engineers 50(3):885-900.

Mudgal, A., C. Baffaut, S.H. Anderson, E.J. Sadler, and A.L. Thompson. 2010. APEX model assessment of variable landscapes on runoff and dissolved herbicides. Transactions of the American Society of Agricultural and Biological Engineers 53(4):1047-1058.

Neitsch, S.L., J.G. Arnold, J.R. Kiniry, and J.R. Williams. 2011. Soil and water assessment tool theoretical documentation version 2009. College Station, TX:Texas Water Resources Institute.

O'Callaghan, J.F., and D.M. Mark. 1984. The extraction of drainage networks from digital elevation data. Computer Vision, Graphics, and Image Processing 28(3):323-344.

Panagopoulos, Y., C. Makropoulos, and M. Mimikou. 2012. Decision support for diffuse pollution management. Environmental Modelling and Software 30(April):57-70. Pennock, D.J. 2005. Precision conservation for co-management of carbon and nitrogen on the Canadian prairies. Journal of Soil and Water Conservation 60(6):396-401.

Pennock, D.J., B.J. Zebarth, and E. DeJong. 1987. Landform classification and soil distribution in hummocky terrain, Saskatchewan, Canada. Geoderma 40(3-4):297-315.

Priestley, C., and R. Taylor. 1972. On the assessment of surface heat flux and evaporation using large-scale parameters. Monthly Weather Review 100(2):81-92.

Pyo, J., S.S. Baek, M. Kim, S. Park, H. Lee, J.S. Ra, and K.H. Cho. 2017. Optimizing Agricultural Best Management Practices in a Lake Erie watershed. Journal of the American Water Resources Association 53(6):1281-1292.

Qin, C.Z., A.X. Zhu, X. Shi, B.L. Li, T. Pei, and C.H. Zhou. 2009. Quantification of spatial gradation of slope positions. Geomorphology 110(3-4):152-161.

Qin, C.Z., A.X. Zhu, W.L. Qiu, Y.J. Lu, B.L. Li, and T. Pei. 2012. Mapping soil organic matter in small low-relief catchments using fuzzy slope position information. Geoderma 171-172(February):64-74.

Liu, J.Z., A.X. Zhu, C.Z. Qin, H. Wu, and J.C. Jiang. 2016. A two-level parallelization method for distributed hydrological models. Environmental Modelling and Software 80(June):175-184.

Maier, H.R., Z. Kapelan, J. Kasprzyk, J. Kollat, L.S. Matott, M.C. Cunha, G.C. Dandy, M.S. Gibbs, E. Keedwell, A. Marchi, A. Ostfeld, D. Savic, D.P. Solomatine, J.A.Vrugt, A.C. Zecchin, B.S. Minsker, E.J. Barbour, G. Kuczera, F.

Rodriguez, H.G., J. Popp, C. Maringanti, and I. Chaubey. 2011. Selection and placement of best management practices used to reduce water quality degradation in Lincoln Lake watershed. Water Resources Research 47(1):1-13.

Sahu, M., and R.R. Gu. 2009. Modeling the effects of riparian buffer zone and contour strips on stream water quality. Ecological Engineering 35(8):1167-1177. 


\section{Figure 11}

Comparison of the best management practice (BMP) scenarios selected randomly by the near Pareto optimal solutions of the 10oth generation from (a) the proposed approach ( $47.7 \%$ reduction rate of soil erosion and $C N ¥ 1.22$ million net cost) and (b) the random approach (47.9\% reduction rate of soil erosion and CN¥1.15 million net cost). CM is closing measures, ABHMP is arbor-bushherb mixed plantation, LQFI is low-quality forest improvement, and $\mathrm{OI}$ is orchard improvement.

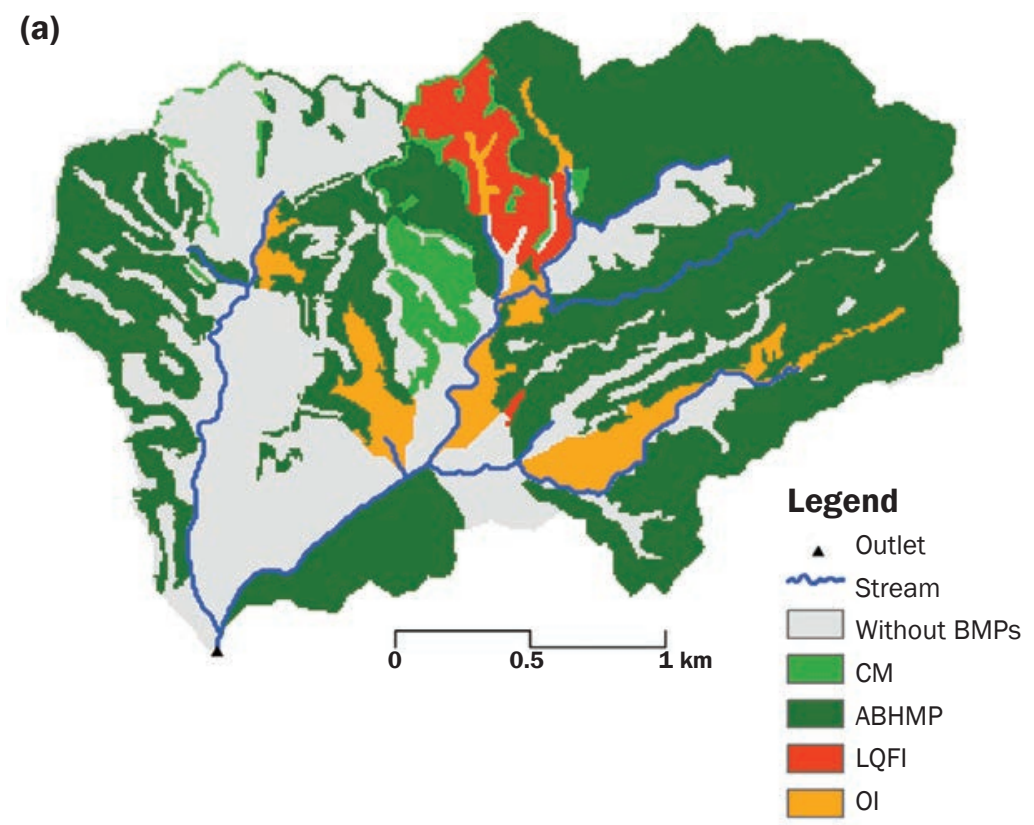

(b)

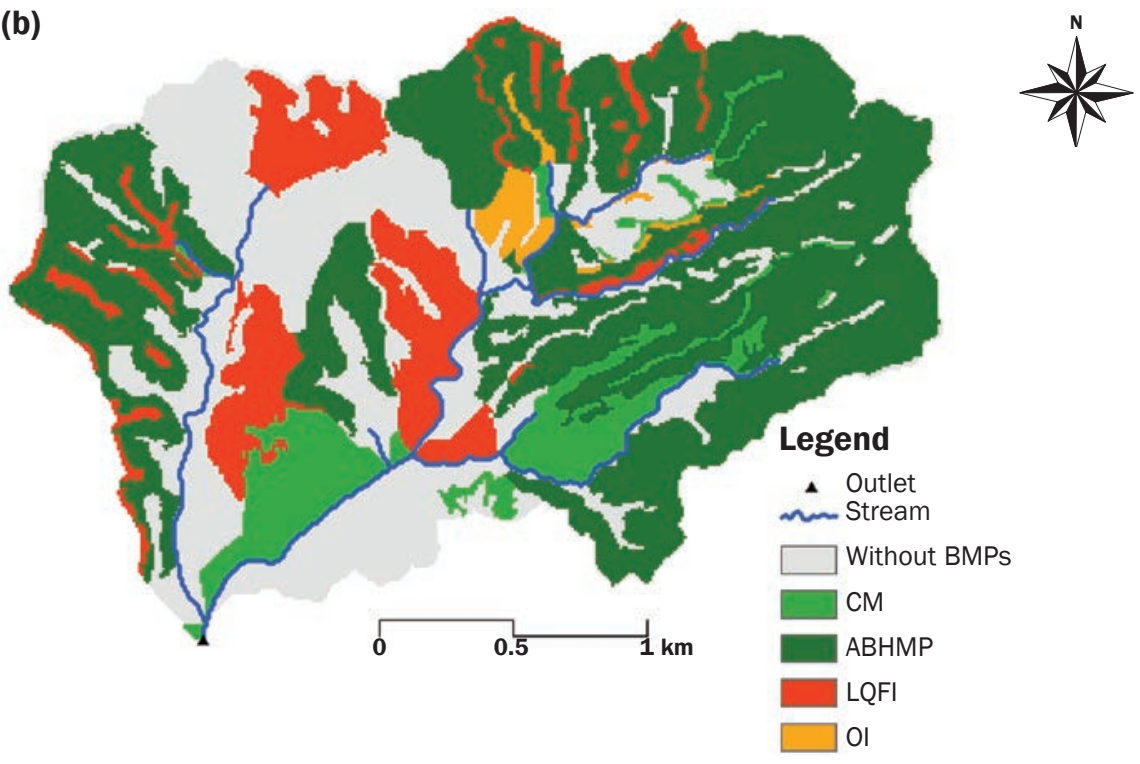

Saxton, K.E., and W.J. Rawls. 2006. Soil water characteristic estimates by texture and organic matter for hydrologic solutions. Soil Science Society of America Journal 70(5):1569-1578.

Schmidt, J., and A. Hewitt. 2004. Fuzzy land element classification from DTMs based on geometry and terrain position. Geoderma 121(3-4):243-256.

Srivastava, P., J.M. Hamlett, and P.D. Robillard. 2003 Watershed optimization of agricultural best management practices: Continuous simulation versus design storms. Journal of the American Water Resources Association 39(5):1043-1054.

Swanson, FJ., T.K. Kratz, N. Caine, and R.G. Woodmansee. 1988. Landform effects on ecosystem patterns and processes. BioScience 38(2):92-98.

Turpin, N., P. Bontems, G. Rotillon, I. Bärlund, M. Kaljonen, S. Tattari, F. Feichtinger, P. Strauss, R. Haverkamp, and M. Garnier. 2005. AgriBMPWater: Systems approach to environmentally acceptable farming. Environmental Modelling and Software 20(2):187-196.

Veith, T.L., M.L. Wolfe, and C.D. Heatwole. 2004. Costeffective BMP placement: Optimization versus targeting. Transactions of the American Society of Agricultural Engineers 47(5):1585-1594.

Wang, X.Q. 2008. Comprehensive benefits evaluation of soil erosion control models and establishing the control paradigm in red soil region. Master dissertation, Huazhong Agricultural University, Wuhan, China (in Chinese with English abstract).

Williams, J.R. 1975. Sediment-yield prediction with universal equation using runoff energy factor. In Present and Prospective Technology for Predicting Sediment Yield and Sources, 244-252. Washington, DC: USDA.

Williams, J.R. 1980. SPNM, a model for predicting sediment, phosphorus, and nitrogen yields from agricultural basins. Journal of the American Water Resources Association 16(5):843-848.

Williams, J.R. 1995. The EPIC model. In Computer Models of Watershed Hydrology, ed. V.P. Singh, 909-1000. Highlands Ranch, CO: Water Resources Publications.

Wu, H., A.X. Zhu, J.Z. Liu, Y.B. Liu, and J.C. Jiang. 2018. Best management practices optimization at watershed scale: Incorporating spatial topology among fields. Water Resources Management 32(1):155-177, doi:10.1007/ s11269-017-1801-8.

Xie, J., C.Z. Qin, G.R. Xiao, L. Yang, Q.L. Lei, J.Z. Liu, and A.X. Zhu. 2015. Soil property mapping using fuzzy clustering method in small watershed of the red soil region in southern China: A case study of Zhuxi watershed. Science of Soil and Water Conservation 13(5):132-139 (in Chinese with English abstract).

Yang, G.X., and E.P.H. Best. 2015. Spatial optimization of watershed management practices for nitrogen load reduction using a modeling-optimization framework. Journal of Environmental Management 161(September):252-260.

Zhu, L.J., A.X. Zhu, C.Z. Qin, and J.Z. Liu. 2018 Automatic approach to deriving fuzzy slope positions. Geomorphology 304(March):173-183, doi: 10.1016/j. geomorph.2017.12.024.

Zitzler, E., M. Laumanns, and L. Thiele. 2001. SPEA2: Improving the strength Pareto evolutionary algorithm. Zurich, Switzerland: Computer Engineering and Networks Laboratory (TIK) Department of Electrical Engineering Swiss Federal Institute of Technology (ETH). Zitzler, E., and L. Thiele. 1999. Multiobjective evolutionary algorithms: A comparative case study and the strength Pareto approach. IEEE Transactions on Evolutionary Computation 3(4):257-271.

Zitzler, E., L.Thiele, M. Laumanns, C.M. Fonseca, andV.G. da Fonseca. 2003. Performance assessment of multiobjective optimizers: An analysis and review. IEEE Transactions on Evolutionary Computation 7(2):117-132. 